\title{
Dynamic Changes of Typical Blowouts Based on High-Resolution Data: A Case Study in Hulunbuir Sandy Land, China
}

\author{
Yi Yang, ${ }^{1,2}$ Chao Guan, ${ }^{1}$ and Eerdun Hasi ${ }^{1}$ \\ ${ }^{1}$ College of Resources Science \& Technology, Beijing Normal University, Beijing 100875, China \\ ${ }^{2}$ National Computer Network Emergency Response Technical Team/Coordination Center of China, Shanghai 201315, China \\ Correspondence should be addressed to Chao Guan; gc471603869@126.com
}

Received 30 November 2016; Revised 29 January 2017; Accepted 15 February 2017; Published 21 March 2017

Academic Editor: Hasi Bagan

Copyright (C) 2017 Yi Yang et al. This is an open access article distributed under the Creative Commons Attribution License, which permits unrestricted use, distribution, and reproduction in any medium, provided the original work is properly cited.

\begin{abstract}
Blowouts are an important ground indication of wind-sand activity in the Hulunbuir grassland. They include two basic geomorphologic units, erosion depression and sand deposition, and three typical morphological types: saucer type, trough type, and compound type. In this study, the dynamic changes of typical blowouts within the past decade were analyzed via multiperiod highresolution remote sensing images. RTK was used to repeatedly measure the blowouts to obtain their high-precision 3D terrain data in 2010, 2011, and 2012. Short-term dynamic changes in 3D blowout morphology were carefully analyzed to discover the following. (1) From 2002 to 2012, the depressions of typical blowouts exhibited downwind extension and lateral expansion trends, as they continuously grew in size. Regarding the sand deposition zones, those of the saucer blowout grew continuously, while those of the trough and compound blowouts fluctuated between growth and contraction. (2) The erosion depression of saucer blowouts eroded downward and spread horizontally; that of trough blowouts first accumulated then eroded but also spread horizontally. The erosion depression of compound blowouts exhibited horizontal spreading accompanied with bottom accumulation. The sand deposition zones of all three types of blowouts exhibited decreasing length with increasing width and height.
\end{abstract}

\section{Introduction}

As one of the main Aeolian landforms of sandy grasslands, the formation and development of blowouts are also the main driving factors driving landscape patterns heterogeneity. Blowouts are created by a variety of factors including wind conditions, precipitation, air temperature, and vegetation coverage; their root causes are the enhanced surface erosion capability of sandstorms and decreased erosion resistance at the surface soil layer. Damage to surface soil and vegetation leads to the direct exposure of sandy materials to wind erosion, which is the direct impetus of a blowout [1-4]. Research on sandy grassland blowouts in China has been concentrated mainly in the Hulunbuir Sandy Land. Dong and Ya [5] and Feng and Wang [6], for example, have found through satellite remote sensing monitoring that the sandy land of Hulunbuir grassland is dominated by grassland desertification accounting for $99 \%$ of the total desertification area. Further, the land desertification is rapidly expanding. Nie et al. [7] assert that the human destruction of grassland vegetation and surface soil is the direct cause of desertification. Zan and Sun [8] found that the vegetation status generally improved between 1982 and 2006 in the eastern part of the Hulunbuir grassland but deteriorated in the western part. Sand belt degradation was particularly obvious in the southern part, where vegetation slightly degraded. Zhang et al. [9] and Man et al. [10] surveyed the small vegetation communities of bare, semibare, and fixed blowouts and their corresponding sand deposition zones in the Hulunbuir grassland to find that the coverage of small vegetation communities in three types of blowouts and sand deposition zones are altogether smaller than those of the native Stipa grandis community, having decreased in the order of fixed blowouts, semibare blowouts, and bare blowouts. Du et al. [11] forecasted the landscape pattern development in their study area from 2012 to 2020 via CA-Markov model and found that the grassland area of Hulunbuir 

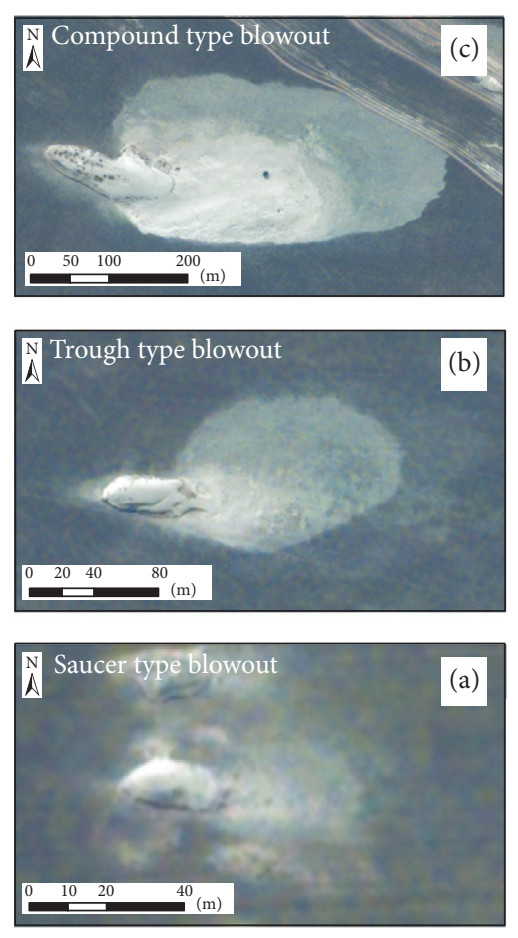

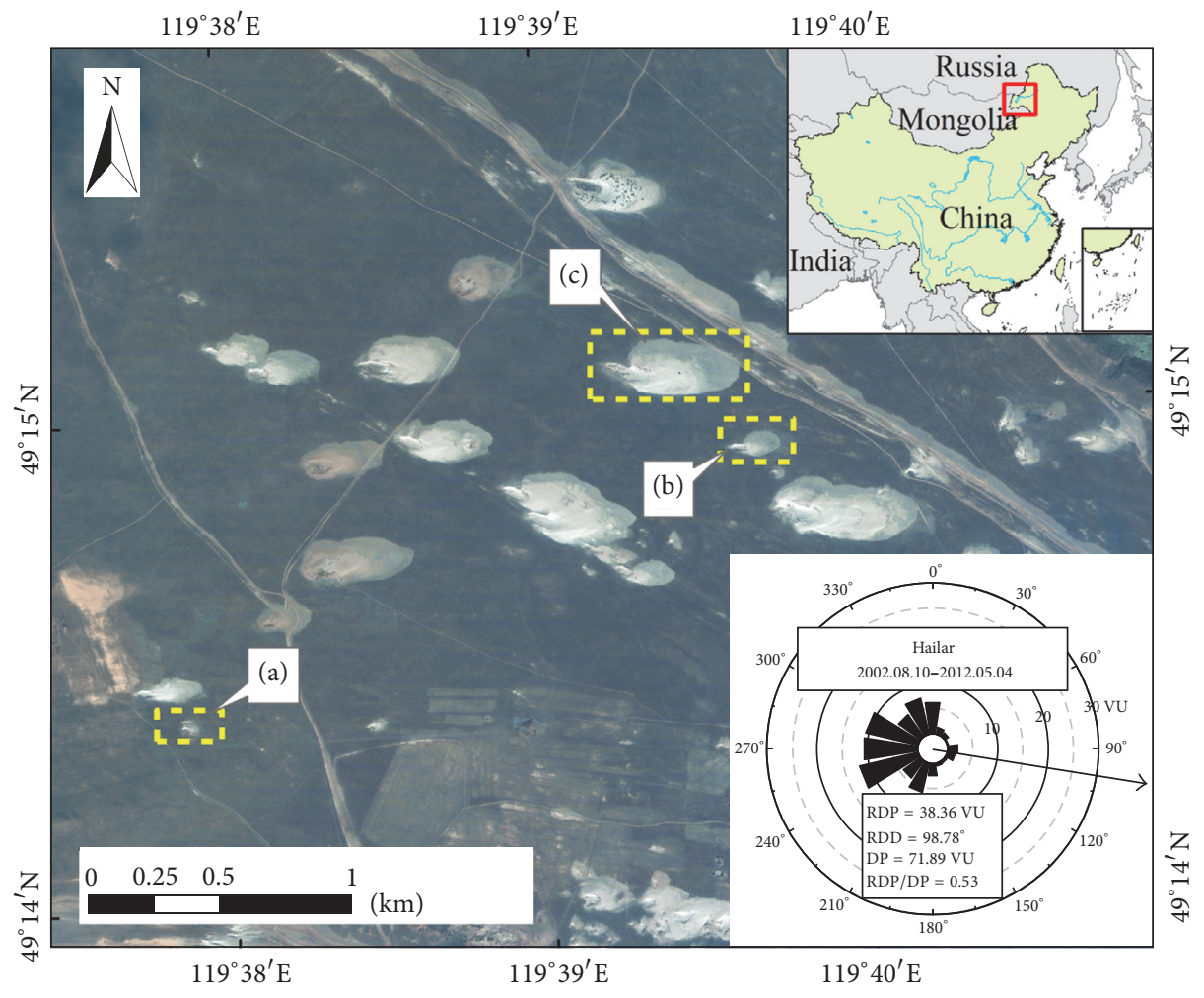

Figure 1: Location of the study area of the Hulunbuir Sandy Land: three different types of blowouts are regarded as the research objects; they are saucer blowout (a), trough blowout (b), and compound blowout (c), respectively, whose size increases sequentially. Meteorological data are obtained from Hailar Meteorological Station. The data includes daily maximum wind velocity and wind direction from 2002 to 2012. Fryberger's Drift Potential Index [12] is used to calculate the total drift potential (DP), resultant drift potential (RDP), and resultant drift direction (RDD); the formula is $\mathrm{DP}=U^{2}\left(U-U_{t}\right) t$. Since $U$ is required to be the average wind velocity, while data in this paper is the maximum wind velocity, conversion is performed by regarding the empirical value of 8.8 studied by Fang et al. [13] as the parameter, that is, $\mathrm{DP}_{\max }=8.8 \mathrm{DP}_{\text {average }}$. The prevailing wind direction in the study area is northwesterly; the RDP value is less than $200 \mathrm{VU}$, indicating of a low wind energy environment [12]. The basemap is QuickBird satellite image of the Hulunbuir Sandy Land in 2002.

decreased while the area of other land cover types increased. Despite these valuable contributions to the literature, there has been little research on the dynamic variation of typical blowouts based on high-precision morphometry combined with remote sensing image analysis. In the present study, we analyzed the dynamic changes in typical sandy grassland blowouts by obtaining relevant morphological through highprecision remote sensing images and RTK measurements. The results presented here may provide scientific basis for the rational utilization of grasslands and for the effective prevention and control of desertification therein.

\section{Overview of Study Area and Research Objects}

The study area is located in the border area between Hailar City and Old Barag Banner of Inner Mongolia Autonomous Region (Figure 1). The area is a flat grassland north of the eastern Hailar Sand Belt section and south of the Hailar River, with an elevation of $620-630 \mathrm{~m}$, on which blowouts are scattered. Zonal vegetation is dominated by Stipa grandis, Stipa krylovii, and Cleistogenes squarrosa. In Aeolian sand covered areas, there are also psammophytes such as Agriophyllum squarrosum. Zonal soil is sandy chestnut soil, with a caliche depth of $0.1-0.3 \mathrm{~m}$, whose parent material is grey fluviolacustrine sands of Hailar Group [1].

Depending on the morphological characteristics, the blowouts in the study area were divided into simple blowouts and compound blowout. Simple blowouts can be subdivided into two types: saucer blowout and trough blowout. In general, trends of dynamic changes vary for different types and sizes of blowouts. Saucer blowouts are generally in the early stage, which are small in size. Trough blowouts are in the middle stage, which are moderate in size. Compound blowouts are in the mature stage, which have large size and complex morphology. Thus, typical saucer blowout (Figure 1(a)), trough blowout (Figure 1(b)), and compound blowout (Figure 1(c)) (with size increasing sequentially) are selected to discuss the processes and causes of their dynamic changes.

2.1. Simple Blowouts. Saucer blowouts are small in scale and shallow in depth, which are mainly in disc, semidisc, or oval shape. There are one or more air outlets on the depressions and soil layer exposed in a "crescent" shape around their 


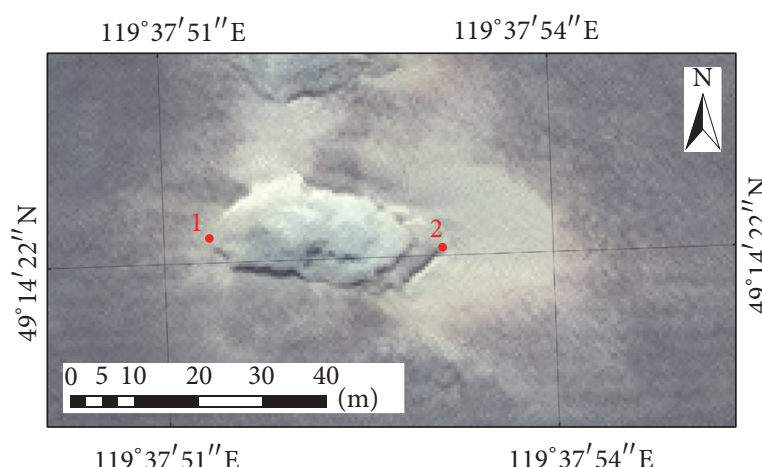

(a)

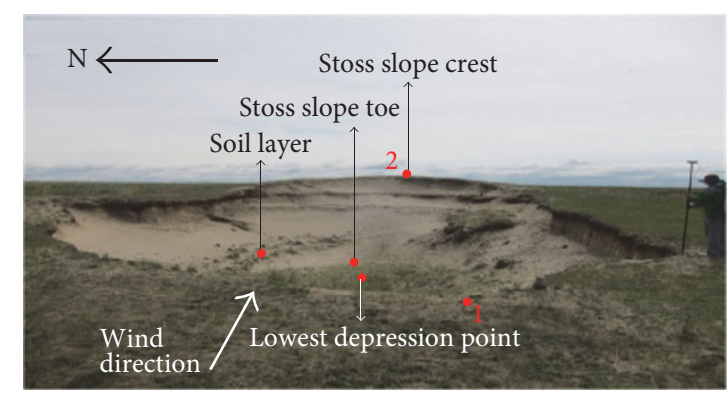

(b)

Figure 2: Morphological characteristics of saucer blowout ((a) WorldView2 data, 2012; (b) Field photographs, 2012).

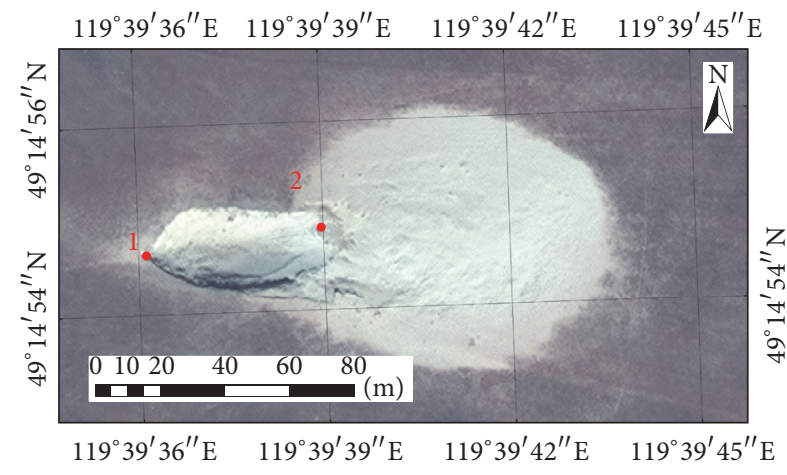

(a)

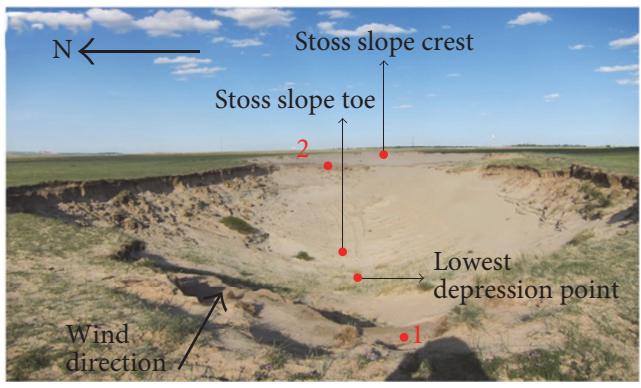

(b)

FIgURE 3: Morphological characteristics of trough blowout ((a) WorldView2 data, 2012; (b) Field photographs, 2012).

rear edge. Inside the depressions, northern walls are relatively gentle, while southern walls are relatively steep. Sand depositions are small in area and thickness, which thinned gradually along with outward spreading (Figure 2).

The trough blowout, per its namesake, forms in a troughlike shape with steep depression sidewalls and a deep bottom. Its sidewalls are prone to collapse, after which they are deposited on the bottom of erosion depressions at a natural angle of repose. There is "crescent" soil layer exposure around the rear edge of the erosion depressions. The sand depositions are large in area, with short and steep stoss slope, round top, and thick deposition that extends and thins gradually along the prevailing wind direction. When the bottom of a largescale trough blowout is eroded to reach the wet sand layer of erosion datum or the clay layer, with strong antiwind erosion capability in the sand layer, the erosion is impeded from flattening the depression bottom (Figure 3).

2.2. Compound Blowouts. Compound blowouts are complex and varied in morphology. Their formation processes can be roughly divided into three categories: (1) compound blowouts formed by the expansion and joining of simple blowouts during their development (Figure 4(a)); (2) compound blowouts formed by the activation of fixed blowouts that have been superimposed on the original depressions or their edges
(Figure 4(b)); and (3) secondary blowouts and parabolic dunes generated by wind erosion in the sand deposition zone of large-scale blowouts (Figure 4(c)). In this paper, the typical compound blowouts shown in Figure 4(c) were selected as the research object.

\section{Data and Methods}

The data used in the study are QuickBird images taken in 2002, 2004, and 2009 as well as WorldView2 images from 2012 (Table 1). Pretreatment of the images is as follows: firstly, panchromatic images are orthorectified with the ground control points; these ground control points are selected on the basis of field measurements using Leica 1230 differential GPS. They include the geometric center of nebkhas in the depression, the inflection points of buildings, and typical trees; the ground control points are evenly distributed within the study area, and the number of points is increased in areas around blowouts. Secondly, image enhancement for more precise extraction of blowout morphological parameters. We chose WGS84 as our data coordinate system; the UTM projection zone was 50 with a central meridian of $117^{\circ} \mathrm{E}$.

Our ground survey of blowout morphology in the study area was carried out primarily with a Leica 1230 differential GPS system. Its nominal planar precision is $10 \mathrm{~mm}+1 \mathrm{ppm}$ 


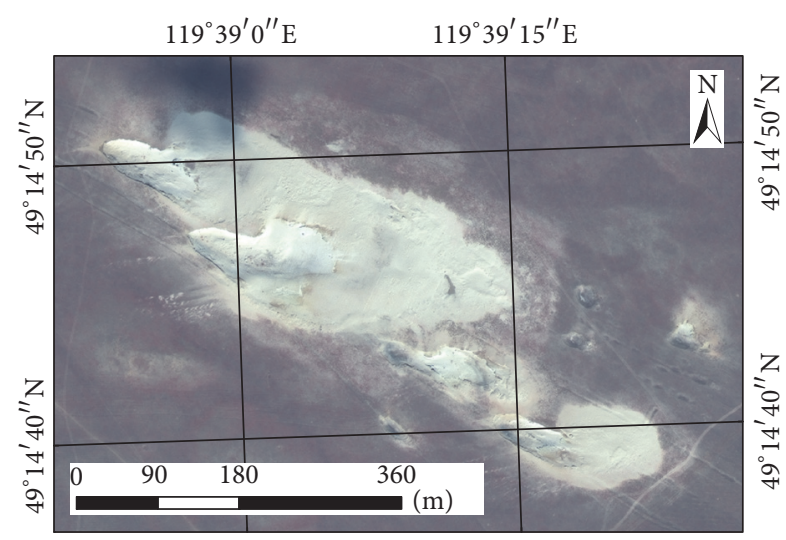

$119^{\circ} 39^{\prime} 0^{\prime \prime} \mathrm{E}$

(a)

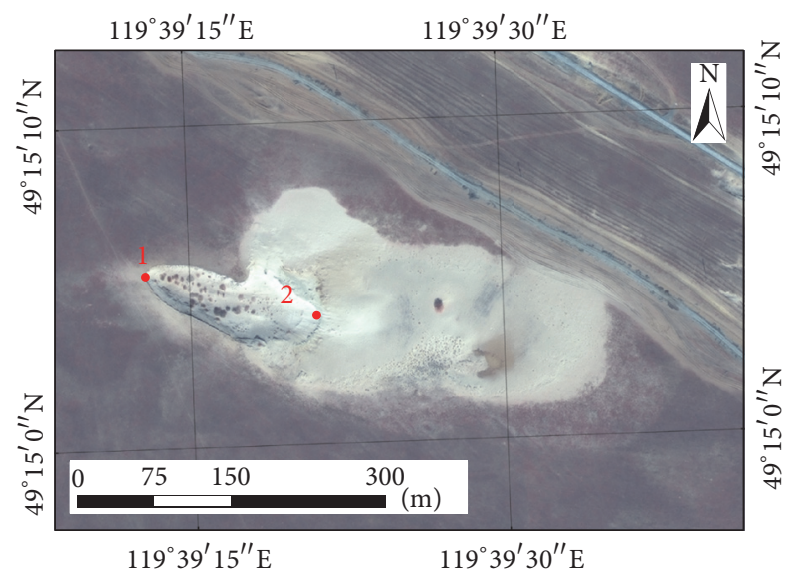

(c)

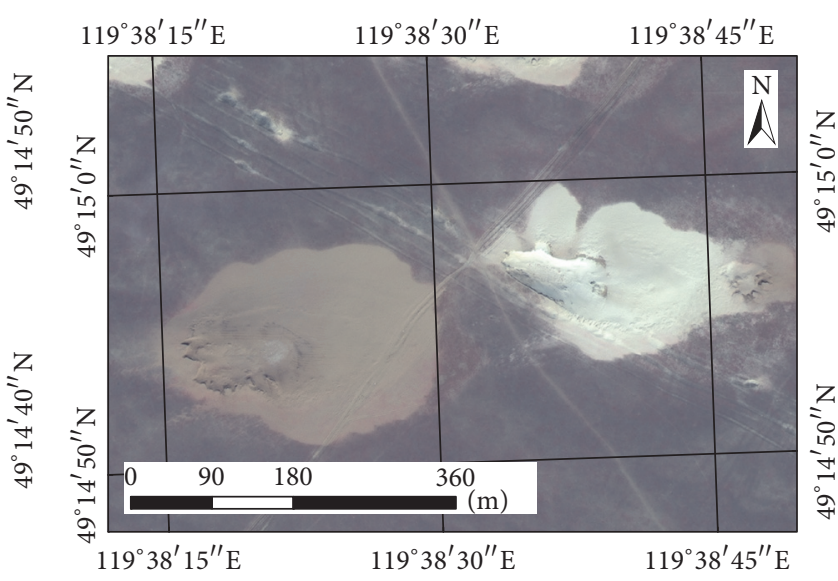

(b)

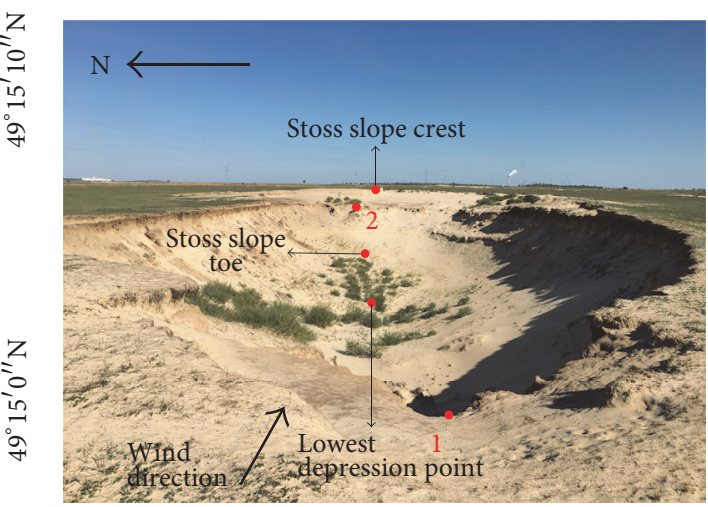

(d)

Figure 4: Compound blowouts ((a), (b), (c) WorldView2 data, 2012; (d) Field photographs, 2012).

TABLE 1: Remote sensing image parameters.

\begin{tabular}{lcc}
\hline Type & Time & Mean cloudiness \\
\hline & 2002.08 .10 & $<10 \%$ \\
QuickBird & 2004.05 .22 & $<10 \%$ \\
& 2009.04 .09 & $<10 \%$ \\
WorldView2 & 2012.05 .04 & $<20 \%$ \\
\hline
\end{tabular}

and its vertical precision is $20 \mathrm{~mm}+1 \mathrm{ppm}$. Measurements were taken in May 2010, September 2011, and June 2012. The collected three-period high-precision differential GPS data were imported into the ArcGIS 9.3 software. The main processing steps were as follows: (1) the outer blowout boundary, erosion depression zone boundary, and sand deposition zone boundary were outlined according to the point names in the attribute table, and the area and morphological parameters of the erosion depression and sand deposition zones were calculated; (2) DEM data of blowouts were generated by Kriging spatial interpolation; (3) on the basis of regional DEM, the interpolation of region was cut utilizing the outer blowout boundary to obtain the DEM data within the scope of blowouts. The volume and $3 \mathrm{D}$ morphological parameters of the erosion depression and sand deposition zones were calculated using ArcGIS 9.3's Area and Volume Statistic tool; (4) contour lines were generated based on the DEM data to analyze the overall elevation changes of blowouts; (5) longitudinal profiles of blowouts and transverse profiles of erosion depressions and sand deposition zone were created using ArcGIS 9.3's Interpolate Shape tool to obtain the profile change map for different regions of blowouts; (6) based on the profile change map, the dynamic changes of characteristic parts were statistically analyzed.

\section{Results}

4.1. Dynamic Change of Typical Blowouts. Figure 5 presents the morphological changes of different blowout types from 2002 to 2012. Saucer blowouts were the smallest in area and exhibited the lowest variation in amplitude. Within the tenyear study period, the erosion depression zone was dominated by the expansion of rear depression edges along the long axis of depression. The sand deposition zone, on the other hand, experienced southwestward expansion from 2002 to 2004 and then decreased in area from 2004 to 2009, showing contraction towards the erosion depression zone; 

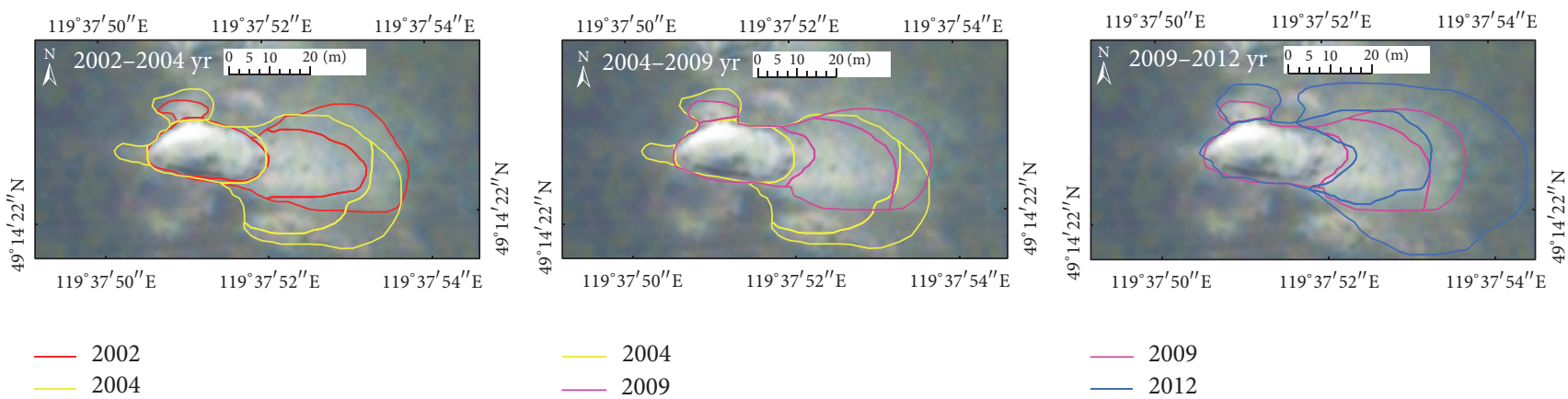

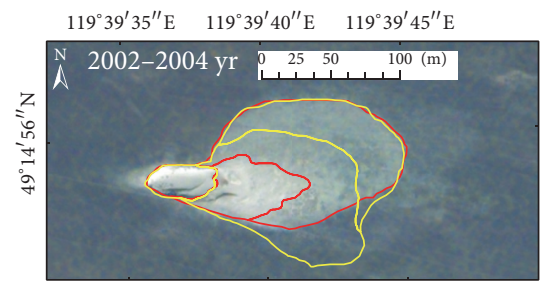

$119^{\circ} 39^{\prime} 35^{\prime \prime} \mathrm{E} \quad 119^{\circ} 39^{\prime} 40^{\prime \prime} \mathrm{E} \quad 119^{\circ} 39^{\prime} 45^{\prime \prime} \mathrm{E}$

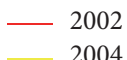

$119^{\circ} 39^{\prime} 10^{\prime \prime} \mathrm{E} 119^{\circ} 39^{\prime} 20^{\prime \prime} \mathrm{E} 119^{\circ} 39^{\prime} 30^{\prime \prime} \mathrm{E} 119^{\circ} 39^{\prime} 40^{\prime \prime} \mathrm{E}$

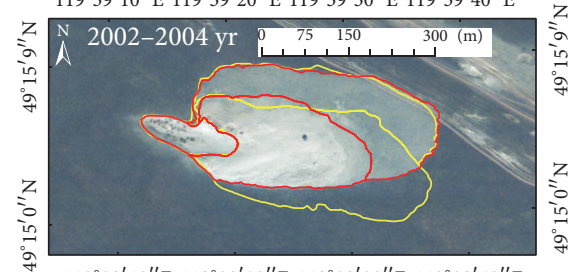

$119^{\circ} 39^{\prime} 10^{\prime \prime} \mathrm{E} 119^{\circ} 39^{\prime} 20^{\prime \prime} \mathrm{E} 119^{\circ} 39^{\prime} 30^{\prime \prime} \mathrm{E} 119^{\circ} 39^{\prime} 40^{\prime \prime} \mathrm{E}$

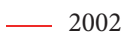

2004

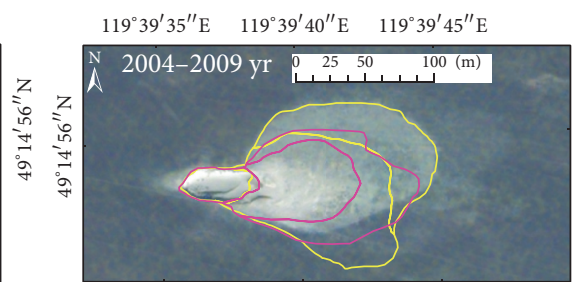

$119^{\circ} 39^{\prime} 35^{\prime \prime} \mathrm{E} \quad 119^{\circ} 39^{\prime} 40^{\prime \prime} \mathrm{E} \quad 119^{\circ} 39^{\prime} 45^{\prime \prime} \mathrm{E}$

2004

2009

(b)

$119^{\circ} 39^{\prime} 10^{\prime \prime} \mathrm{E} 119^{\circ} 39^{\prime} 20^{\prime \prime} \mathrm{E} 119^{\circ} 39^{\prime} 30^{\prime \prime} \mathrm{E} 119^{\circ} 39^{\prime} 40^{\prime \prime} \mathrm{E}$

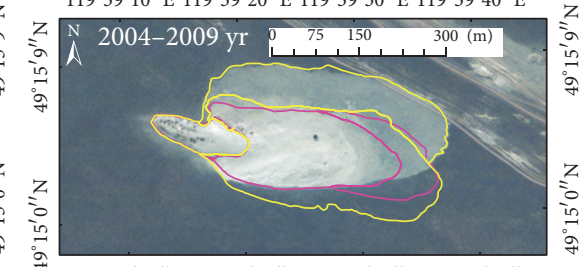

$119^{\circ} 39^{\prime} 10^{\prime \prime} \mathrm{E} 119^{\circ} 39^{\prime} 20^{\prime \prime} \mathrm{E} 119^{\circ} 39^{\prime} 30^{\prime \prime} \mathrm{E} 119^{\circ} 39^{\prime} 40^{\prime \prime} \mathrm{E}$

2004

2009

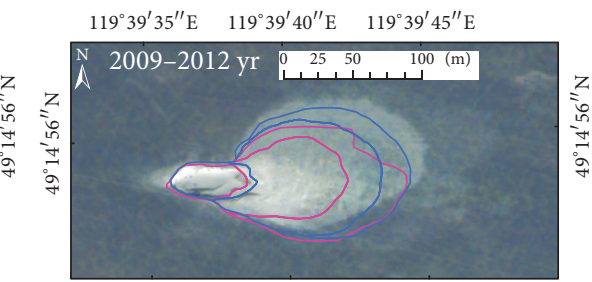

$119^{\circ} 39^{\prime} 35^{\prime \prime} \mathrm{E} \quad 119^{\circ} 39^{\prime} 40^{\prime \prime} \mathrm{E} \quad 119^{\circ} 39^{\prime} 45^{\prime \prime} \mathrm{E}$

2009

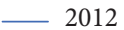

$119^{\circ} 39^{\prime} 10^{\prime \prime} \mathrm{E} 119^{\circ} 39^{\prime} 20^{\prime \prime} \mathrm{E} 119^{\circ} 39^{\prime} 30^{\prime \prime} \mathrm{E} 119^{\circ} 39^{\prime} 40^{\prime \prime} \mathrm{E}$

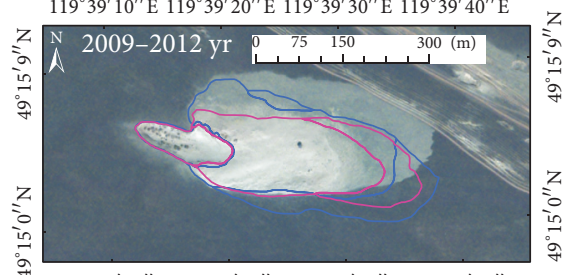

$119^{\circ} 39^{\prime} 10^{\prime \prime} \mathrm{E} 119^{\circ} 39^{\prime} 20^{\prime \prime} \mathrm{E} 119^{\circ} 39^{\prime} 30^{\prime \prime} \mathrm{E} 119^{\circ} 39^{\prime} 40^{\prime \prime} \mathrm{E}$

$-2009$

(c)

FIGURE 5: Morphological changes of different blowout types ((a) saucer blowout, (b) trough blowout, and (c) compound blowout; QuickBird images, 2002).

again in 2012, the zone expanded northwestward. Trough blowouts varied in amplitude to a lesser extent than compound blowouts.

From 2002 to 2004, erosion in the depression zone occurred mainly around the eastern edge and manifested as an expansion of the depression along the long axes. The sand deposition zone expanded rapidly to the surroundings, primarily towards the southwest. The sand drift zone was partially transformed into a sand deposition zone which expanded outward towards the northeast in the sand deposition zone. From 2004 to 2009, the eastern edge of the erosion depression zone expanded considerably and the soil layer moved forward along the prevailing wind direction due to erosion; the sand deposition zone and sand drift zone diminished due to the interannual compound blowout variations.

From 2009 to 2012, expansion in the erosion depression zone occurred mainly around the southeastern edge, while the sand deposition zone expanded to the north and east. The compound blowout changed most significantly within the ten-year study period. From 2002 to 2004, erosion in the depression zone occurred mainly in the northeastern and eastern edges, while the soil layer exposed around the eastern edge moved forward along the long axis of depression due to wind erosion. The sand deposition zone expanded eastward and southeastward due to prevailing west and northwesterly winds. Sand drift zone was transformed into sand deposition zone along with the accumulation of sand materials.

From 2004 to 2009, erosion in the compound blowout depression zone occurred mainly in the southeastern and northeastern edges, primarily exhibiting increased width of depression. Vegetation fixation strengthened due to the abrupt decrease in resultant drift potential from 2004 to 2009, thus leading to the rapid reduction of sand deposition and sand drift zones during that period which contracted in the 


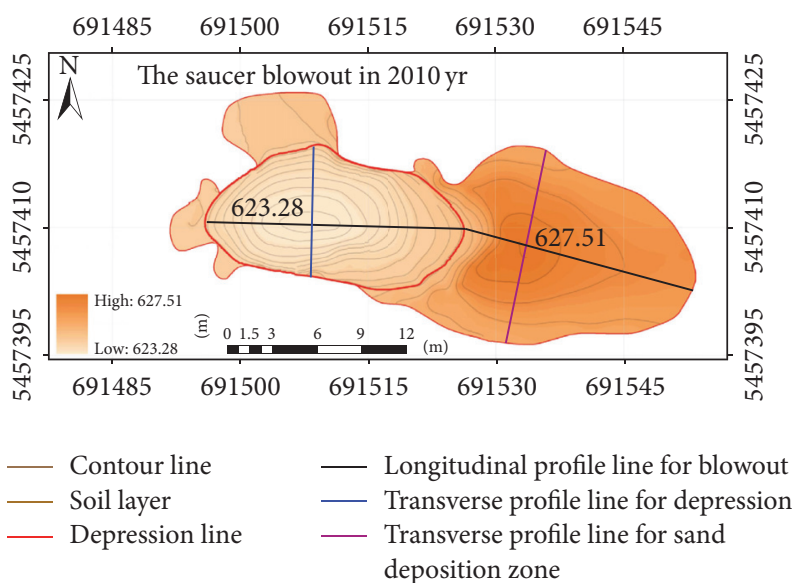

(a)

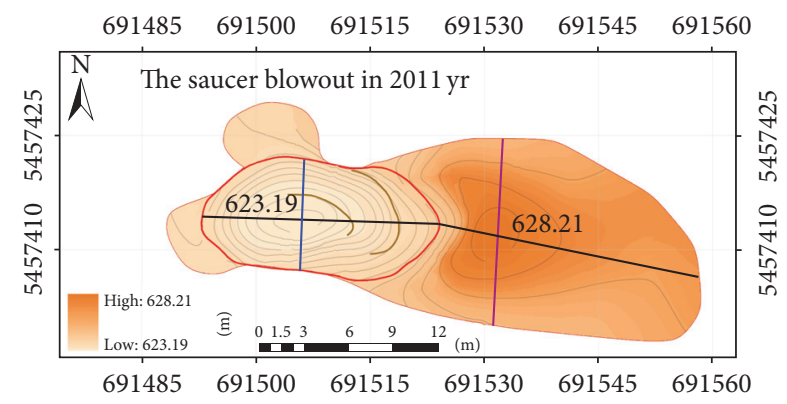
- Contour line
- Soil layer
- Depression line

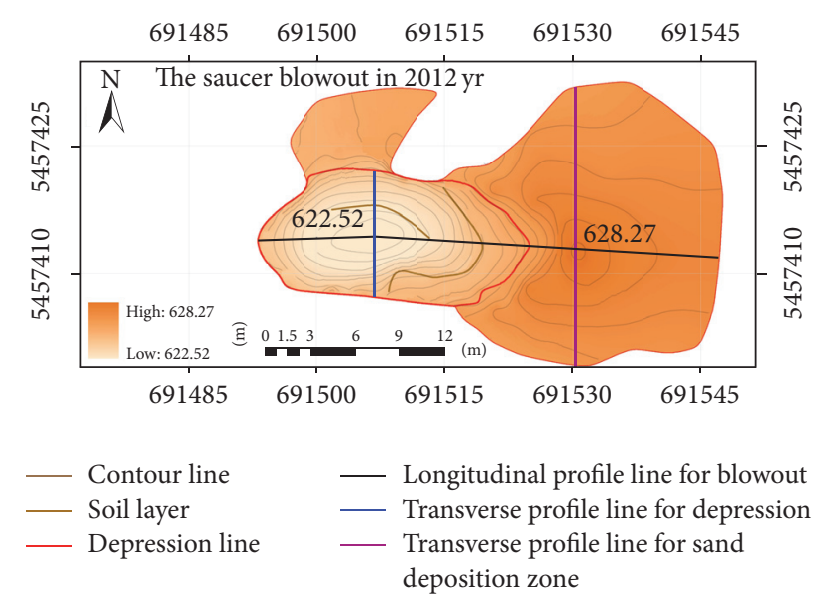

(c)

Figure 6: DEM variations of saucer blowout from 2010 to 2012.

erosion depression zone direction. From 2009 to 2012, major eroded sites in the depression zone formed the northeastern, eastern, and southeastern edges; the length and width of the depression continued to increase. The sand deposition zone expanded northward and eastward, while the sand drift zone expanded at the southern part of the sand deposition zone.

\subsection{Dynamic Change of Typical Blowouts Based on RTK Ground Survey}

4.2.1. Morphological Changes of Saucer Blowout. As shown in Figure 6, the tested saucer blowout erosion depression zone was discoid with the depression opening in the WNW prevailing wind direction. The depression elevation was more stable compared to that that of the trough blowout. Northern, southern, and eastern edges of the depression were similar in slope. There were two layers of crescent soil layer exposure at the bottom and northeastern edges of the depression which retreated due to abrasion. The sand deposition zone was fanshaped with a convex stoss slope and gradually decreasing lee slope elevation towards the surrounding areas. A new air outlet was formed on the northern edge of the depression as airflow entered it and generated a vortex due to the shallow saucer blowout, ultimately forming a small-scale, fan-shaped sand deposition zone at the northern part of the depression.

Table 2 lists the changes in various saucer blowout zone areas from 2010 to 2012. Overall, the areas of erosion depression and sand deposition zones increased; the growth amplitude was far higher for the sand deposition zone (44.4\%) than the erosion depression zone (6.3\%). From 2010 to 2011, the area of the erosion depression zone increased by $19.4 \mathrm{~m}^{2}$ with a relative growth amplitude of $5.3 \%$, exceeding that of the 2011 to 2012 period $(0.9 \%)$. The area of the sand deposition zone increased sharply with a relative growth amplitude from 2010 to 2011 (43.7\%) far greater than that from 2011 to $2012(0.5 \%)$, similar to the interannual growth trend of the erosion depressions. These results indicate that the expansion amplitude of the saucer blowout area from 2010 to 2011 was greater than that from 2011 to 2012 .

Table 3 lists the changes in saucer blowout morphological parameters. The length, width, depth, and volume of the blowouts presented continuous growth trends. The growth rate of depression length was $0.7 \mathrm{~m} \cdot \mathrm{a}^{-1}$, with small growth amplitude $(4.5 \%)$, while width growth rate was $0.5 \mathrm{~m} \cdot \mathrm{a}^{-1}$ 
TABLE 2: Changes in saucer blowout area (unit: $\mathrm{m}^{2}$ ).

\begin{tabular}{lccccc}
\hline Zone & 2010 & 2011 & 2012 & Variation of area & Variation amplitude \\
\hline Erosion depression zone & 362.7 & 382.1 & 385.5 & 22.8 & $6.3 \%$ \\
Sand deposition zone & 669.6 & 962.0 & 967.1 & 297.5 & $44.4 \%$ \\
Total area & $1,032.3$ & $1,344.1$ & $1,352.6$ & 320.3 & $31.0 \%$ \\
\hline
\end{tabular}

TABLE 3: Changes in morphological parameters for saucer blowout erosion depression zone.

\begin{tabular}{lccccc}
\hline Morphological parameter & 2010 & 2011 & 2012 & Variation quantity & Variation amplitude \\
\hline Length $(\mathrm{m})$ & 31.1 & 31.4 & 32.5 & 1.4 & $4.5 \%$ \\
Width $(\mathrm{m})$ & 14.8 & 15.5 & 15.8 & 1.0 & $6.8 \%$ \\
Depth $(\mathrm{m})$ & 3.5 & 3.7 & 3.8 & 0.3 & $8.6 \%$ \\
Volume $\left(\mathrm{m}^{3}\right)$ & 558.0 & 559.6 & 571.4 & 13.4 & $2.4 \%$ \\
\hline
\end{tabular}

TABLE 4: Changes in morphological parameters for saucer blowout sand deposition zone.

\begin{tabular}{lccccc}
\hline Variable & 2010 & 2011 & 2012 & Variation quantity & Variation amplitude \\
\hline Length $(\mathrm{m})$ & 27.6 & 35.1 & 22.3 & -5.3 & $-19.2 \%$ \\
Width $(\mathrm{m})$ & 23.7 & 25.6 & 33.6 & 9.9 & $41.8 \%$ \\
Height $(\mathrm{m})$ & 2.8 & 2.9 & 3.1 & 0.3 & $10.7 \%$ \\
Volume $\left(\mathrm{m}^{3}\right)$ & $1,162.8$ & $1,741.7$ & $1,723.1$ & 560.3 & $48.2 \%$ \\
\hline
\end{tabular}

with large growth amplitude (6.8\%). Depression depth slowly increased with growth amplitude of $8.6 \%$; depression volume also continuously increased, with a growth amplitude of $2.4 \%$ and a growth rate of $6.7 \mathrm{~m}^{3} \cdot \mathrm{a}^{-1}$.

Table 4 lists the changes in morphological parameters for the saucer blowout sand deposition zone. The length of the sand deposition zone first increased then decreased with an overall reduction amplitude of $19.2 \%$. The length increased from 2010 to 2011 with relative growth amplitude of $27.2 \%$. From 2011 to 2012 , the length decreased sharply by $12.8 \mathrm{~m}$ with a relative reduction amplitude of $36.5 \%$. Width, on the other hand, continued to increase at a rate of $5 \mathrm{~m} \cdot \mathrm{a}^{-1}$. The height of the sand deposition zone also continued to increase at a flat growth rate. The total volume of the sand deposition zone fluctuated, increasing to $1,741.7 \mathrm{~m}^{3}$ (relative growth amplitude of $49.8 \%$ ) in 2011 , and then decreased slowly to $1,723.1 \mathrm{~m}^{3}$ (relative reduction amplitude of $1.1 \%$ ) in 2012. The volume and length of the sand deposition zone showed the same variation trends and did not increase as width and height increased.

To further investigate these morphological parameters using 3D GPS data, we studied the profile variations of blowouts and changes in the movement of various characteristic parts between 2010 and 2012 by extracting longitudinal blowout profiles and transverse erosion depressions and sand deposition zone profiles. We first draw layers of the longitudinal and transverse profile lines and then cut the DEM of saucer blowout according to the respective layers using the Interpolate Shape tool in ArcGIS 9.3's 3D Analyst module. Profile graphs were generated using the Create Profile Graph tool. As shown in Figure 7, the geomorphic units of saucer blowout consisted of an air inlet, erosion depression bottom, rear depression edge, and the windward and lee slopes of the sand deposition zone. The saucer blowout depressions

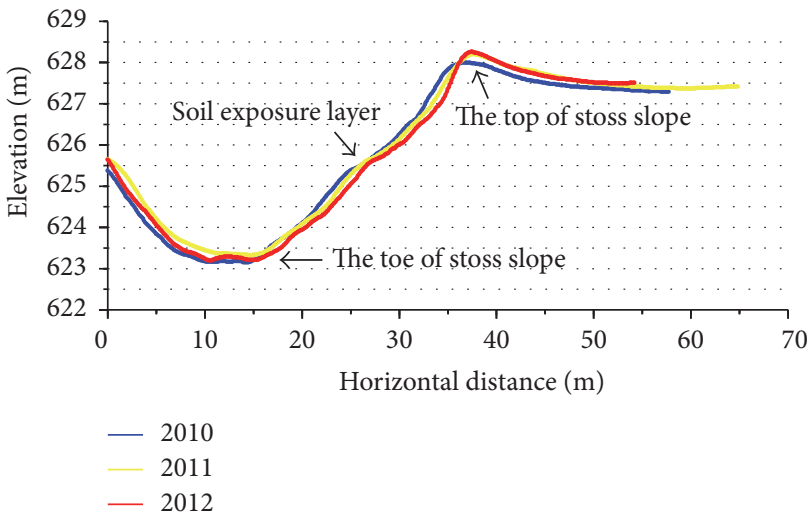

FIgURE 7: Longitudinal profile variations of saucer blowout from 2010 to 2012.

had gentle slopes; the slope of the front edge was between 14 and $16^{\circ}$. The depression bottom was relatively flat. The slope of the rear edge was smaller than that of the front edge $\left(8-10^{\circ}\right)$. There was crescent soil layer exposure at the top of the rear depression edge, and the stoss slope of the sand deposition zone was concave. The slope of the middle section was relatively gentle, between 10 and $12^{\circ}$. The stoss slope was steeper, between 29 and $31^{\circ}$. The lee slope of sand deposition zone was concave and with gradually decreasing elevation along the long axis of the blowouts.

As shown in Figure 7, the depression gradually deepened while the rear depression edge and stoss slope of the sand deposition zone were subject to apparent wind erosion. The soil layer moved forward along the long axis of the depression due to erosion and the stoss slope crest elevation increased due to the accumulation of sand materials. 
TABLE 5: Changes in various characteristic points of saucer blowout (unit: m).

\begin{tabular}{lcccccc}
\hline & \multicolumn{2}{c}{ Stoss slope toe } & \multicolumn{2}{c}{ Soil layer } & \multicolumn{2}{c}{ Stoss slope crest } \\
& Horizontal distance & Elevation & Horizontal distance & Elevation & Horizontal distance & Elevation \\
\hline 2010 & 14.3 & 623.4 & 24.8 & 625.6 & 625.6 & 36.2 \\
2011 & 15.2 & 623.4 & 26.3 & 625.5 & 37.1 & 37.3 \\
2012 & 15.3 & 623.2 & 27.0 & -0.1 & 628.2 \\
Variations & 1.0 & -0.2 & 2.2 & & 628.3 \\
\hline
\end{tabular}

To obtain the annual changes in horizontal distance and elevation of each characteristic part for the saucer blowout, the slopes of all points on the profile line were calculated. Then, the range of characteristic parts was determined based on Figure 7. Within this range, the second derivatives of all points were calculated, and the point with the largest slope change within this region was obtained, which was precisely the characteristic point of the characteristic part (Figure 7). The horizontal distance (the distance from the air inlet to the characteristic point) and elevation of the characteristic point were recorded. By this way, the horizontal migration distance and elevation values of stoss slope toe, soil layer, stoss slope crest, and lowest depression point in various years were obtained as shown in Table 5 .

Table 5 shows where the stoss slope toe of the blowouts moved forward by $1.0 \mathrm{~m}$ along the long axis of the depression due to wind erosion, with an annual mean movement of $0.5 \mathrm{~m} \cdot \mathrm{a}^{-1}$ and elevation reduction of $0.2 \mathrm{~m}$. From 2010 to 2011, the slope toe moved forward by $0.9 \mathrm{~m}$, showing much faster movement than 2011-2012. Soil layer at the rear edge of the erosion depression moved forward by $2.2 \mathrm{~m}$ along the long axis as a result of severe wind erosion attributed to terrain uplift, airflow compression, and continuously increasing wind speed, with an annual mean movement of $1.1 \mathrm{~m} \cdot \mathrm{a}^{-1}$. From 2010 to 2011, the soil layer moved by $1.5 \mathrm{~m}$; that is, it moved much faster than it did in 2011-2012 $(0.7 \mathrm{~m})$. Soil layer elevation was relatively stable from 2010 to 2011 and decreased by $0.1 \mathrm{~m}$ from 2011 to 2012 . The stoss slope crest increased overall due to airflow dispersion and reduced wind speed. Its horizontal forward movement was $1.1 \mathrm{~m}$ and its annual mean movement was $0.6 \mathrm{~m} \cdot \mathrm{a}^{-1}$. There was also greater migration distance from 2010 to $2011(0.9 \mathrm{~m})$ than that from 2011 to $2012(0.2 \mathrm{~m})$. Its elevation steadily increased with an overall increase of $0.2 \mathrm{~m}$.

The transverse depression profiles (Figure 8) show where the northern and southern slopes of erosion depressions were asymmetrical. The northern slopes were relatively gentle $\left(18-20^{\circ}\right)$, whereas the southern slopes were relatively steep $\left(23-25^{\circ}\right)$. The depression bottoms were smooth. From 2010 to 2012, the depressions formed an erosion pattern and elevations of the northern slopes, southern slopes, and bottoms decreased as a result of wind erosion. The southern slopes were gentle, so they became the air outlet after the airflow formed a vortex in the blowouts, thereby resulting in the fan-shaped sand deposition zone in the northern part of the depression.

Figure 9 shows the sand deposition zone transverse profile variations. Accumulation was common throughout this

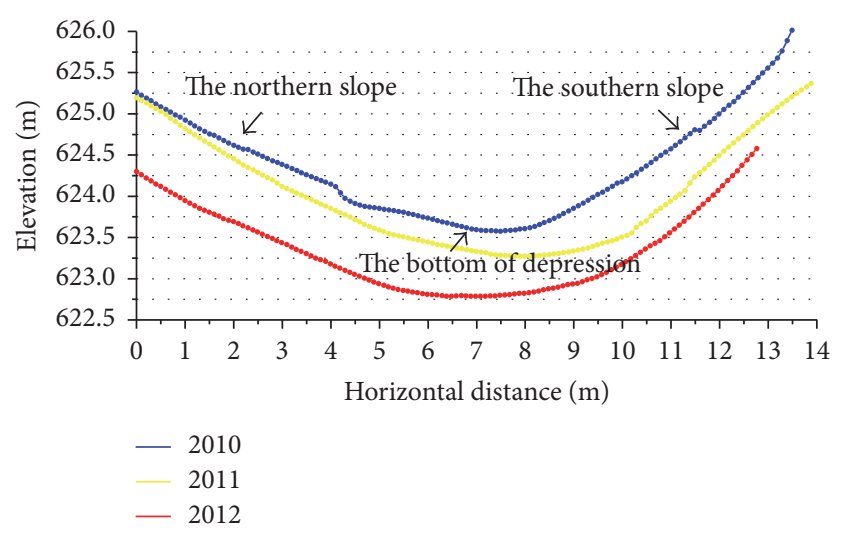

FIGURE 8: Transverse profile variations of saucer blowout erosion depression zone from 2010 to 2012.

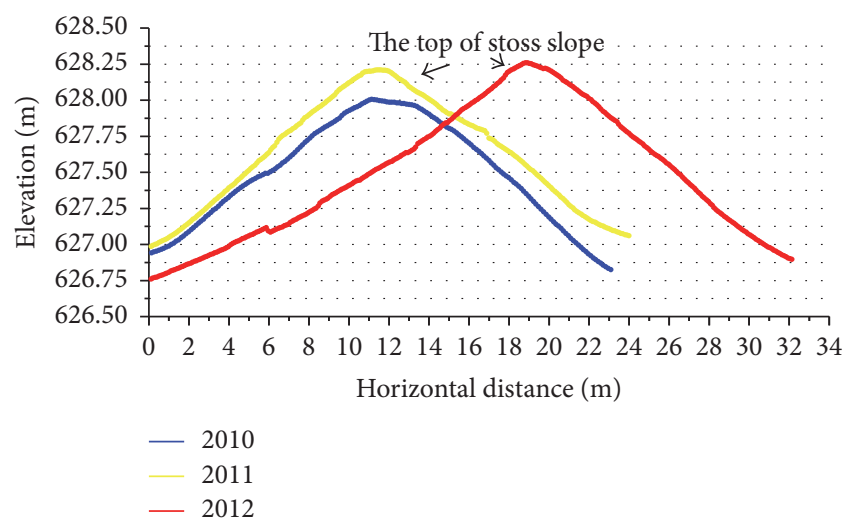

FIGURE 9: Transverse profile variations of saucer blowout sand deposition zone from 2010 to 2012.

zone. The stoss slope crest was the highest in elevation and spread to the surrounding areas with gradually decreasing elevation. From 2010 to 2012, the sand deposition zone continued to grow in height, while moving gradually southward due to the influence of the prevailing wind direction. The stoss slope crest increased by $0.2 \mathrm{~m}$ in elevation and moved horizontally southward by $7.3 \mathrm{~m}$ at a rate of $3.6 \mathrm{~m} \cdot \mathrm{a}^{-1}$ from 2010 to 2012. It moved by $1.0 \mathrm{~m}$ from 2011 to 2012 and then by as much as $6.3 \mathrm{~m}$ from 2011 to 2012 . The southern boundary of the deposition zone also expanded southward, moving by $0.9 \mathrm{~m}$ from 2010 to 2011 by $8.0 \mathrm{~m}$ from 2011 to 2012 .

4.2.2. Morphological Changes of Trough Blowout. Based on our field survey and DEM data analysis (Figure 10), trough 
TABLE 6: Changes in trough blowout area (unit: $\mathrm{m}^{2}$ ).

\begin{tabular}{lccccc}
\hline Zone & 2010 & 2011 & 2012 & Variation of area & Variation amplitude \\
\hline Erosion depression zone & $1,254.4$ & $1,257.5$ & $1,360.9$ & 106.5 & $8.5 \%$ \\
Sand deposition zone & $4,831.4$ & $6,079.8$ & $6,562.3$ & $1,730.9$ & $35.8 \%$ \\
Total area & $6,085.8$ & $7,337.3$ & $7,923.2$ & $1,837.4$ & $30.2 \%$ \\
\hline
\end{tabular}
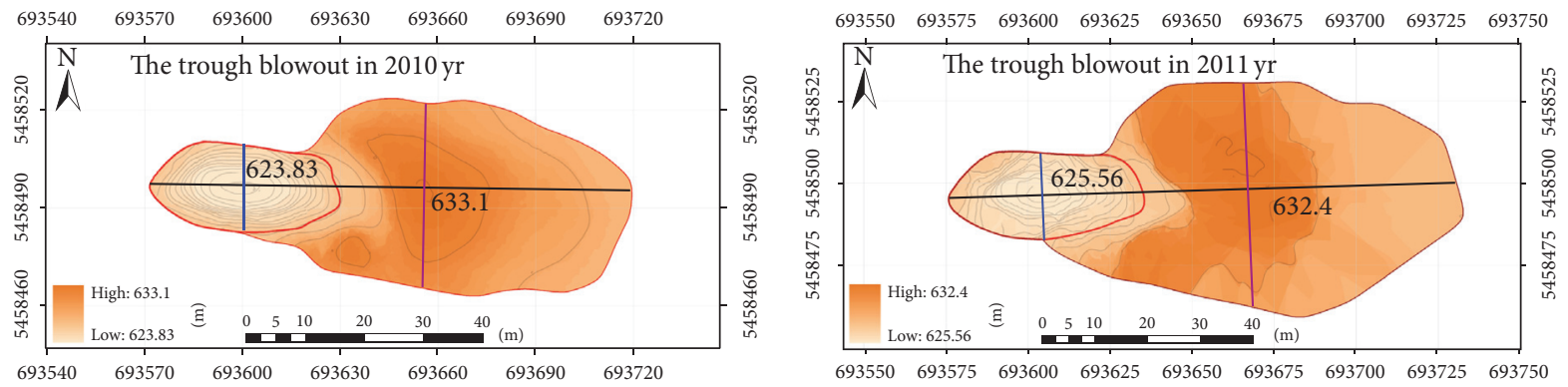

$\begin{array}{ll}- \text { Contour line } & \text { Transverse profile line for } \\ \text { Depression line } & \text { depression } \\ \text { Longitudinal profile line for } & \quad \text { Transverse profile line for } \\ \text { blowout } & \text { sand deposition zone }\end{array}$

(a)

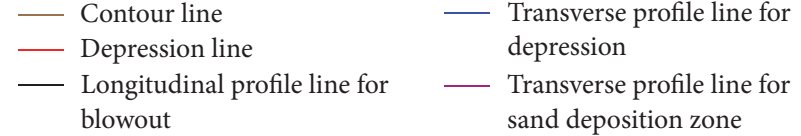

(b)

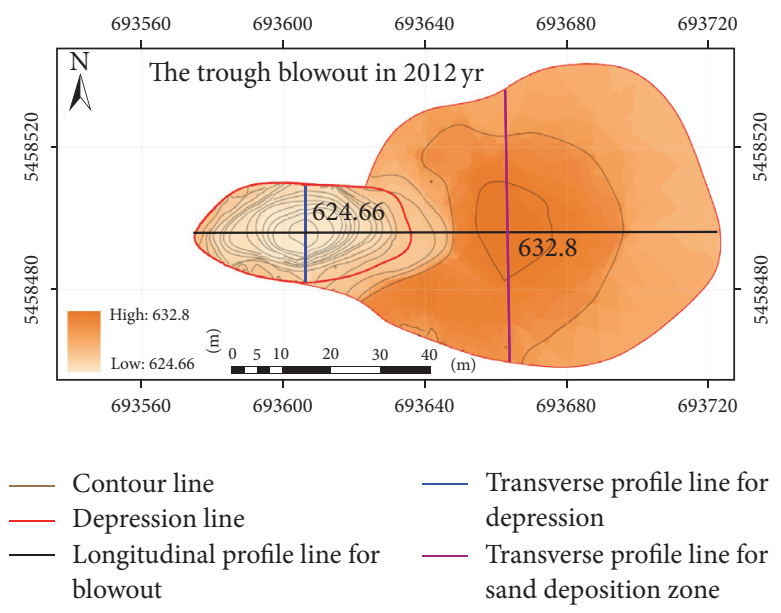

(c)

FIGURE 10: DEM variations of trough blowout from 2010 to 2012.

blowouts occurred in the erosion depression zone and the sand deposition zone. The erosion depression zone was oblong in shape with its opening facing westward, which is consistent with the prevailing wind direction. The elevation of the depression changed substantially over the study period. The northern and southern edges were relatively steep; the northeastern edge expanded due to wind erosion and the stoss slope at the eastern edge was concave. Crescent soil layer exposure occurred and retreated due to abrasion, thereby enabling the erosion depression zone to develop along the long axis of depression. The sand deposition zone had a convex stoss slope and a lee slope that gradually decreased in elevation.

Table 6 describes the changes in trough blowout area. The trough blowout's erosion depression zone area was generally more stable than that of the sand deposition zone from 2010 to 2012 ; their variation amplitudes were $8.5 \%$ and $35.8 \%$, respectively, with respective growth rates of $53.3 \mathrm{~m}^{2} \cdot \mathrm{a}^{-1}$ and $865.5 \mathrm{~m}^{2} \cdot \mathrm{a}^{-1}$. The area of the sand deposition zone increased by $1,248.4 \mathrm{~m}^{2}$ from 2010 to 2011, showing relative growth amplitude of $25.8 \%$; from 2011 to 2012, its relative growth amplitude was only $8.0 \%$.

Table 7 lists the changes in trough blowout morphological parameters: those of erosion depressions altogether increased, as did volume. The length and width of the depression continually increased, with similar growth amplitudes of $5.3 \%$ and $5.1 \%$, respectively. The depth of the depression decreased from $6.5 \mathrm{~m}$ in 2010 to $6.0 \mathrm{~m}$ in 2011 and then increased to $7.0 \mathrm{~m}$ in 2012. Depression volume fluctuated in a similar pattern, suggesting that it was controlled by the 
TABLE 7: Changes in morphological parameters for trough blowout erosion depression zone.

\begin{tabular}{lccccc}
\hline Morphological parameter & 2010 & 2011 & 2012 & Variation quantity & Variation amplitude \\
\hline Length $(\mathrm{m})$ & 60.9 & 61.1 & 64.1 & 3.2 & $5.3 \%$ \\
Width $(\mathrm{m})$ & 27.2 & 27.4 & 28.6 & 7.4 & $5.1 \%$ \\
Depth $(\mathrm{m})$ & 6.5 & 6.0 & 7.0 & 0.8 & $12.9 \%$ \\
Volume $\left(\mathrm{m}^{3}\right)$ & $4,022.3$ & $3,960.7$ & $5,055.1$ & $1,032.8$ & $25.7 \%$ \\
\hline
\end{tabular}

TABLE 8: Changes in morphological parameters for trough blowout sand deposition zone.

\begin{tabular}{lccccc}
\hline Morphological parameter & 2010 & 2011 & 2012 & Variation quantity & Variation amplitude \\
\hline Length $(\mathrm{m})$ & 90.2 & 98.8 & 86.6 & -3.6 & $-4.0 \%$ \\
Width $(\mathrm{m})$ & 60.5 & 72.4 & 85.5 & 25.0 & $41.3 \%$ \\
Height $(\mathrm{m})$ & 2.4 & 2.8 & 2.9 & 0.5 & $20.8 \%$ \\
Volume $\left(\mathrm{m}^{3}\right)$ & $7,564.1$ & $13,089.3$ & $13,303.2$ & $5,739.1$ & $75.9 \%$ \\
\hline
\end{tabular}

changes in depression depth rather than increasing with the increase in length and width.

As shown in Table 8, the length of the trough blowout sand deposition zone was fairly stable with a reduction amplitude of only $4.0 \%$. The length increased from $90.2 \mathrm{~m}$ in 2010 to $98.8 \mathrm{~m}$ in 2011 and then decreased again to $86.6 \mathrm{~m}$. Its width grew continuously at a rate of $12.5 \mathrm{~m} \cdot \mathrm{a}^{-1}$. The length-width ratio was close to $1: 1$, indicating that the sand deposition zone in the trough blowout gradually became fan-shaped. Its height increased by $0.5 \mathrm{~m}$ with a growth amplitude of $20.8 \%$. The volume of the sand deposition zone increased at a rate as high as $2,869.6 \mathrm{~m}^{3} \cdot \mathrm{a}^{-1}$ and amplitude of $75.9 \%$.

The longitudinal profiles of trough blowouts and transverse profiles of their depressions and sand deposition zones were extracted with the same analytical method as that used to extract the saucer blowout profiles. As shown in Figure 11, the front edge of erosion depressions was relatively steep with slopes between 16 and $20^{\circ}$. The depression was smooth on the bottom, which was covered with a small range of psammophyte vegetation. Crescent soil layer exposure was present at the rear upper part of the depression affected by wind erosion. In 2011 and 2012, the stoss slope of the sand deposition zone migrated along the long axis due to wind erosion, and a section of soil layer scarp appeared. The stoss slope of the sand deposition zone was convex in shape ranging within $5-7^{\circ}$ with a rounded crest. Its elevation decreased with the prevailing wind direction, which transited towards the grass basement.

From 2010 to 2012, the trough blowout erosion depression zone first grew and then shrank, whereas the sand deposition zone first shrank and then grew. From 2010 to 2011, the front edge, bottom, and lower rear part of depression all showed an accumulation trend, while, from 2011 to 2012, the depression deepened due to erosion. The upper rear part of the depression presented an erosion pattern. The soil layer moved forward along the long axis of the depression due to wind erosion; the stoss slope of the sand deposition zone was also eroded by wind. The elevation of the stoss slope crest first decreased then increased.

Table 9 shows the variation trends of various characteristic points in the trough blowout. The horizontal distance of

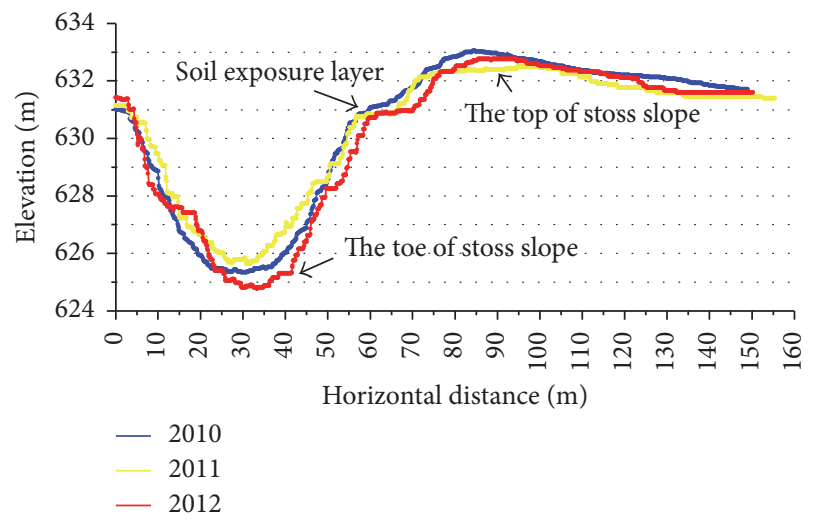

FIGURE 11: Longitudinal profile variations of trough blowout from 2010 to 2012.

the stoss slope toe first decreased and then increased, which is attributed mainly to the accumulation of sand materials at the depression bottom from 2010 to 2011. From 2011 to 2012 , the slope toe was dominated by erosion, with horizontal movement of $5.7 \mathrm{~m}$ and elevation decrease of $0.3 \mathrm{~m}$. The soil exposure layer continued to move forward along the long axis of the depression at a rate of $3.2 \mathrm{~m} \cdot \mathrm{a}^{-1}$, while its elevation remained fairly stable. The elevation of the stoss slope crest first decreased by $0.7 \mathrm{~m}$ from 2010 to 2011 and then increased by $0.4 \mathrm{~m}$ from 2011 to 2012; it decreased overall by $0.3 \mathrm{~m}$ during these years. This was mainly because the depressions were in an accumulation pattern from 2010 to 2011. The sand materials transported to the sand deposition zone diminished in size, and the original sand deposition zone decreased in elevation as a result of wind erosion. From 2011 to 2012, large amounts of sand materials were transported to the sand deposition zone as the depression was severely eroded by wind, resulting in increased elevation of the slope crest in the sand deposition zone.

Figure 12 shows the transverse profile variations of the trough blowout sand deposition zone, which first shrank and then grew over the study period. The elevation of its stoss slope crest decreased by $0.4 \mathrm{~m}$ from 2010 to 2011 and 
TABLE 9: Variations of various characteristic trough blowout points (unit: m).

\begin{tabular}{lcccccc}
\hline & \multicolumn{2}{c}{ Stoss slope toe } & \multicolumn{2}{c}{ Soil layer } & \multicolumn{2}{c}{ Stoss slope crest } \\
& Horizontal distance & Elevation & Horizontal distance & Elevation & Horizontal distance & Elevation \\
\hline 2010 & 35.3 & 625.6 & 55.1 & 630.6 & 62.3 & 633.1 \\
2011 & 32.0 & 625.7 & 56.8 & 630.8 & 92.4 & 632.4 \\
2012 & 41.0 & 625.3 & 61.5 & 630.9 & 0.3 & 3.3 \\
Variations & 5.7 & -0.3 & 6.4 & & -0.3 \\
\hline
\end{tabular}

TABLE 10: Changes in area of compound blowout (unit: $\mathrm{m}^{2}$ ).

\begin{tabular}{lccccc}
\hline Zone & 2010 & 2011 & 2012 & Variation of area & Variation amplitude \\
\hline Erosion depression zone & $8,259.1$ & $8,439.9$ & $8,442.9$ & 183.8 & $2.2 \%$ \\
Sand deposition zone & $41,866.8$ & $46,774.2$ & $49,881.1$ & $8,014.3$ & $19.1 \%$ \\
Total area & $50,125.9$ & $55,214.1$ & $58,324.0$ & $8,198.1$ & $16.4 \%$ \\
\hline
\end{tabular}

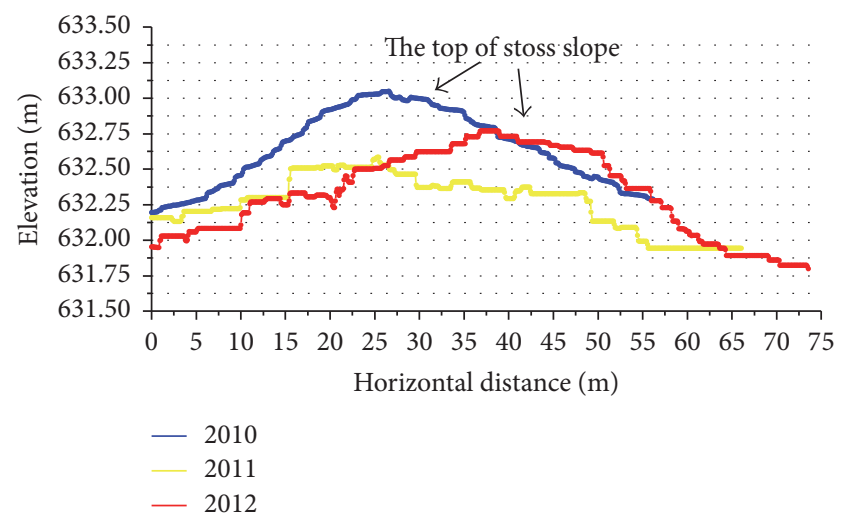

FIGURE 12: Transverse profile variations of trough blowout sand deposition zone between 2010 and 2012 .

increased by $0.2 \mathrm{~m}$ from 2011 to 2012, showing an overall rise of $0.2 \mathrm{~m}$. The horizontal distance of the stoss slope crest moved northward by $3.9 \mathrm{~m}$ from 2010 to 2011 and moved southward by $14.0 \mathrm{~m}$ from 2011 to 2012 , presenting an overall southward movement of $10.1 \mathrm{~m}$.

4.2.3. Morphological Changes of Compound Blowout. We divided the compound blowout as-measured into the erosion depression zone and sand deposition zone based on our field survey and DEM data analysis (Figure 13). The erosion depression zone was oblong in shape and opened towards the WNW prevailing wind direction. The elevation of the depression changed considerably during the study period. The northern and southern edges were relatively steep; the northeastern edge was expanded due to wind erosion and the stoss slope at the eastern edge was concave. Crescent soil layer exposure was present and retreated due to abrasion, thereby enabling the erosion depression zone to develop along the long axis. The sand deposition zone expanded to the southeast. The stoss slope of this zone was convex, while the middle part of the lee slope deviated southeastward. Secondary blowout with low elevation appeared at the sand deposition zone due to differential erosion, behind which a parabolic dune developed with its own stoss slope and slope crest. Sand materials reaccumulated, resulting in increased elevation.

Table 10 describes variations in the measured area of compound blowouts. Various blowout zones mainly exhibited morphological expansion. The variation amplitude was greatest in the sand deposition zone. The area of the erosion depression zone increased by $183.8 \mathrm{~m}^{2}$ with a growth amplitude of $2.2 \%$ and growth rate of $91.1 \mathrm{~m}^{2} \cdot \mathrm{a}^{-1}$. From 2010 to 2011, the area increased by $180.8 \mathrm{~m}^{2}$ with a relative growth amplitude of $2.1 \%$; from 2011 to 2012, the area increased by $3 \mathrm{~m}^{2}$ with a relative growth amplitude of only $0.04 \%$. In other words, the expansion of the depression area slowed down. The area of the sand deposition zone increased by $8014.3 \mathrm{~m}^{2}$, showing a growth amplitude of $19.1 \%$ and growth rate of $4007.2 \mathrm{~m}^{2} \cdot \mathrm{a}^{-1}$. From 2010 to 2011, the area increased by $4907.4 \mathrm{~m}^{2}$ with a relative growth amplitude of $11.7 \%$, while, from 2011 to 2012 , the area increased by $3106.9 \mathrm{~m}^{2}$ with a relative growth amplitude of $6.6 \%$. The decrease in growth amplitude suggests slowed growth overall in the sand deposition zone. The total area increased by $8198.1 \mathrm{~m}^{2}$ (16.4\%). From 2010 to 2011 , the area increased by $5088.2 \mathrm{~m}^{2}$ with a growth amplitude of $10.1 \%$, while, from 2011 to 2012, the area increased by $3109.9 \mathrm{~m}^{2}$, with a growth amplitude of $5.6 \%$. These area variations altogether indicate that various blowout zones increased in area while their growth rates decreased.

Table 11 lists the changes in morphological parameters for the compound blowout erosion depression zone. The length, width, and volume of the erosion depressions increased, while the depth gradually decreased, indicating morphological expansion with simultaneous shallowing. The length of the depression increased by $1.5 \mathrm{~m}$ with a $2.5 \mathrm{~m} \cdot \mathrm{a}^{-1}$ growth rate and growth amplitude of $0.8 \%$ from 2010 to 2011, while, from 2011 to 2012, the length increased by $3.5 \mathrm{~m}$ with a relative growth amplitude of $2.0 \%$. The width of the depression increased by $1.6 \mathrm{~m}$ at a growth rate of $1.3 \mathrm{~m} \cdot \mathrm{a}^{-1}$ and growth amplitude of $2.2 \%$ from 2010 to 2011; the growth amplitude decreased to $1.4 \%$ from 2011 to 2012 as the width increased by $1.0 \mathrm{~m}$. The depth of the depression decreased by $0.9 \mathrm{~m}$ from 2010 to 2011 with a relative reduction amplitude of $8.4 \%$; it decreased by only $0.2 \mathrm{~m}$ from 2011 to 2012 with a relative 
TABLE 11: Changes in morphological parameters for compound blowout erosion depression zone.

\begin{tabular}{lccccc}
\hline Morphological parameter & 2010 & 2011 & 2012 & Variation quantity & Variation amplitude \\
\hline Length $(\mathrm{m})$ & 171.3 & 172.8 & 176.3 & 5.0 & $2.9 \%$ \\
Width $(\mathrm{m})$ & 71.5 & 73.1 & 74.1 & 2.6 & $3.6 \%$ \\
Depth $(\mathrm{m})$ & 10.7 & 9.8 & 9.6 & -1.1 & $-10.3 \%$ \\
Volume $\left(\mathrm{m}^{3}\right)$ & $31,975.4$ & $34,231.1$ & $34,415.5$ & $2,440.1$ & $7.6 \%$ \\
\hline
\end{tabular}

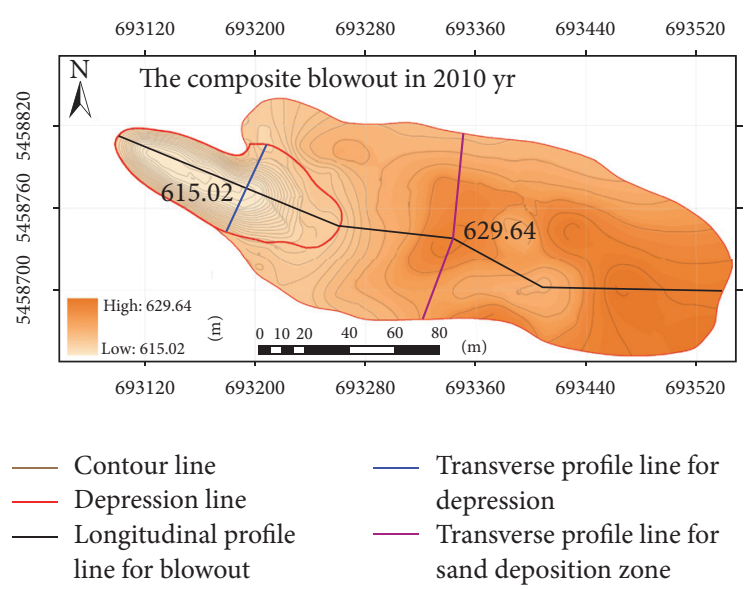

(a)

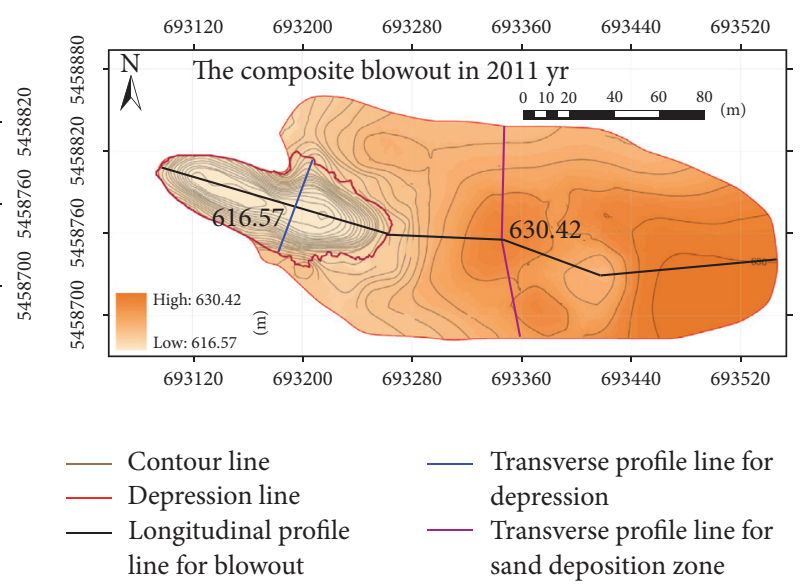

(b)

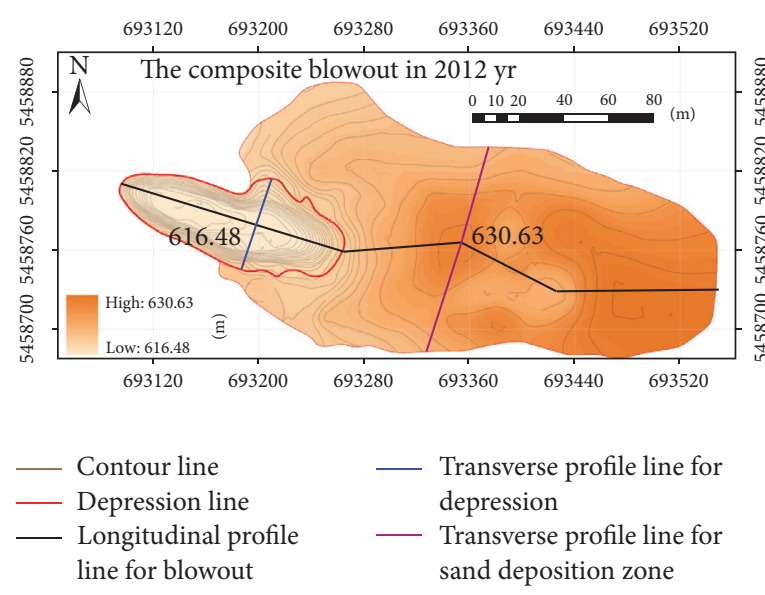

(c)

FIGURE 13: DEM variations of compound blowout from 2010 to 2012.

reduction amplitude of $2.0 \%$, presenting an overall decrease of $1.1 \mathrm{~m}$ with decreased reduction amplitude and reduced accumulation rate. The total volume of erosion depression increased by $2440.1 \mathrm{~m}^{3}$ with a growth amplitude of $7.6 \%$.

Table 12 lists the changes in the sand deposition zone morphological parameters. The length of this zone decreased while its width, height, and total volume all increased over the study period. The length decreased by $3.5 \mathrm{~m}$ with a reduction rate of $1.8 \mathrm{~m} \cdot \mathrm{a}^{-1}$ and reduction amplitudes of $0.2 \%$ from 2010 to 2011 and $1.0 \%$ from 2011 to 2012. The width changed substantially, increasing by $36.8 \mathrm{~m}$ with a growth rate of $18.4 \mathrm{~m} \cdot \mathrm{a}^{-1}$. Its relative growth amplitude was $15.8 \%$ from 2010 to 2011 and $7.4 \%$ from 2011 to 2012 . These results suggest that the growth amplitude of sand deposition zone width was large when the reduction amplitude of length was small; conversely, when the reduction amplitude of length was large, the growth amplitude of width was small. The zone developed into a fan shape due to these changes. The volume growth rate of the sand deposition zone was $39310.9 \mathrm{~m}^{3} \cdot \mathrm{a}^{-1}$, indicating large amounts of sand accumulation in the zone during the study period having led to the rapid growth in volume.

The longitudinal profiles shown in Figure 14 indicate that the compound blowout behaved similarly to the trough blowout in terms of basic geomorphologic units, with the exception of secondary blowouts and parabolic dunes in the sand deposition zone. The front edge of the erosion depression was relatively steep with slopes between 16 and $20^{\circ}$. Salix psammophila shrubs grew abundantly at the bottom 
TABLE 12: Changes in morphological parameters for compound blowout sand deposition zone.

\begin{tabular}{lccccc}
\hline Morphological parameter & 2010 & 2011 & 2012 & Variation quantity & Variation amplitude \\
\hline Length $(\mathrm{m})$ & 290.3 & 289.6 & 286.8 & -3.5 & $-1.2 \%$ \\
Width $(\mathrm{m})$ & 150.7 & 174.5 & 187.5 & 36.8 & $24.4 \%$ \\
Height $(\mathrm{m})$ & 6.4 & 6.7 & 7.3 & 0.9 & $14.1 \%$ \\
Volume $\left(\mathrm{m}^{3}\right)$ & $175,913.1$ & $223,245.9$ & $254,534.9$ & $78,621.8$ & $44.7 \%$ \\
\hline
\end{tabular}

TABLE 13: Variations of various characteristic compound blowout points (unit: $\mathrm{m}$ ).

\begin{tabular}{|c|c|c|c|c|c|c|c|c|}
\hline & \multicolumn{2}{|c|}{ Stoss slope toe } & \multicolumn{2}{|l|}{ Soil layer } & \multicolumn{2}{|c|}{ Stoss slope crest } & \multicolumn{2}{|l|}{ Recession } \\
\hline & Horizontal distance & Elevation & Horizontal distance & Elevation & Horizontal distance & Elevation & Horizontal distance & Elevation \\
\hline 2010 & 93.9 & 616.5 & 144.0 & 624.5 & 247.9 & 629.0 & 325.8 & 627.4 \\
\hline 2011 & 127.4 & 617.6 & 166.1 & 624.9 & 256.2 & 629.5 & 330.8 & 628.2 \\
\hline 2012 & 132.2 & 617.9 & 171.0 & 625.2 & 251.5 & 629.6 & 333.3 & 628.3 \\
\hline Variations & 38.3 & 1.4 & 27.0 & 0.7 & 3.6 & 0.6 & 7.5 & 0.9 \\
\hline
\end{tabular}

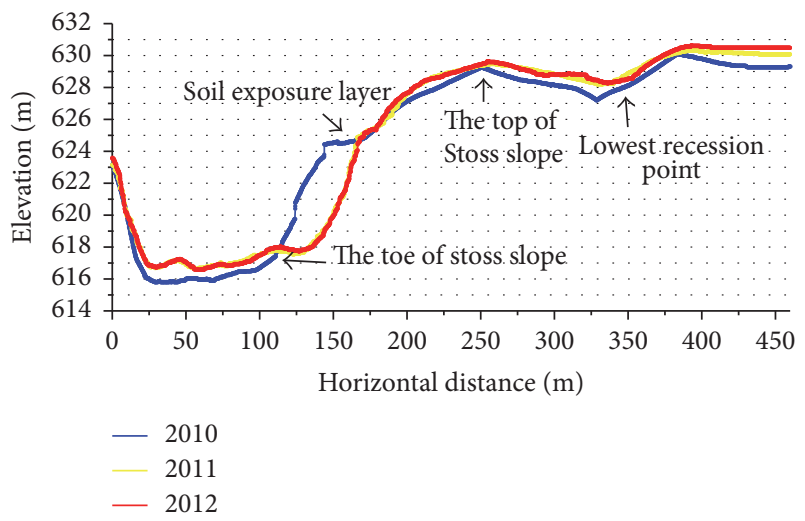

FIGURE 14: Longitudinal profile variations of compound blowout from 2010 to 2012 .

of depression, resulting in a concave-convex curve at the depression bottom. The rear edge of the depression was concave with slopes between 14 and $16^{\circ}$. There was crescent soil layer exposure at the rear upper part of the depression due to wind erosion. The stoss slope of the sand deposition zone was convex with slopes between 4 and $7^{\circ}$. Again, as-affected by wind erosion, small recessions appeared at the lee slope accompanied by reduced elevation and soil exposure. Sand materials also accumulated behind the lee slope with dunes in the stoss slope, again resulting in increased elevation.

As shown in Figure 14, the depth of the compound blowout depression bottom gradually decreased from 2010 to 2012. The rear edge of the depression was severely eroded from 2010 to 2011 but less severely so from 2011 to 2012. From 2010 to 2011, the sand deposition zone exhibited an overall accumulation trend. Sand materials accumulated intensely from 2010 to 2011 but less intensely from 2011 to 2012. Small recessions behind the sand deposition zone developed similarly with an increase in elevation. The horizontal distances and elevations of stoss slope toe, soil exposure layer, stoss slope crest, and lowest recession point in various years were measured as reported in Table 13. From 2010 to 2012, the stoss slope toe moved $38.3 \mathrm{~m}$ along the long axis as a result of wind erosion and increased by $1.4 \mathrm{~m}$ in elevation, indicating that the erosion depression expanded along the long axis due to accumulated sand materials. The increase in horizontal distance was much greater from 2010 to 2011 than from 2011 to 2012 at $33.5 \mathrm{~m}$ and $4.8 \mathrm{~m}$, respectively, suggesting that wind erosion was more severe from 2010 to 2011. The soil layer exposed at the rear tail edge of the erosion depression moved horizontally by $27.0 \mathrm{~m}$, while its elevation increased only $0.7 \mathrm{~m}$. The movement distance for the period from 2010 to 2011 was much greater than that from 2011 to 2012 , at $22.1 \mathrm{~m}$ and $4.9 \mathrm{~m}$, respectively, with a movement rate of $13.5 \mathrm{~m} \cdot \mathrm{a}^{-1}$. The crest of the stoss slope moved $3.6 \mathrm{~m}$ along the long axis and increased $0.6 \mathrm{~m}$ in elevation. The elevation for this characteristic point was fairly stable from 2011 to 2012 but increased by $0.5 \mathrm{~m}$ from 2010 to 2011 . The lowest recession point of the lee slope moved by $7.5 \mathrm{~m}$ along the long axis of the blowout at $5.0 \mathrm{~m}$ and $2.5 \mathrm{~m}$, from 2010 to 2011 and from 2011 to 2012, respectively; that is, the change was more dramatic from 2010 to 2011. An overall increase of $0.9 \mathrm{~m}$ in elevation was also observed.

The transverse profiles of the rear depression edge (Figure 15) indicate that the northern and southern slopes of the depression were asymmetrical. The northern slopes were relatively gentle $\left(6-10^{\circ}\right)$, whereas the southern slopes were rather steep $\left(20-24^{\circ}\right)$. There was also a scarp caused by soil layer exposure at the southern slope. From 2010 to 2012, the bottom of the depression widened from $17.1 \mathrm{~m}$ to $36.3 \mathrm{~m}$ at a $19.2 \mathrm{~m}$ total increase. The elevation of the depression bottom increased and the depression depth became shallower. For this reason, the length of the northern depression slope decreased from $28.5 \mathrm{~m}$ in 2010 to $23.3 \mathrm{~m}$ in 2012 . The southern slope changed similarly. As the southern slope toe was eroded by wind, the soil layer collapsed to generate new collapse surfaces, thereby steepening the slope.

Figure 16 presents the transverse profile variations for the compound blowout sand deposition zone, which was convex and north-south asymmetrical. The southern section of the sand deposition zone was concave and featured secondary blowouts. The elevation of the stoss slope crest increased by $0.6 \mathrm{~m}$ from 2010 to 2012 and its crest moved southward by 


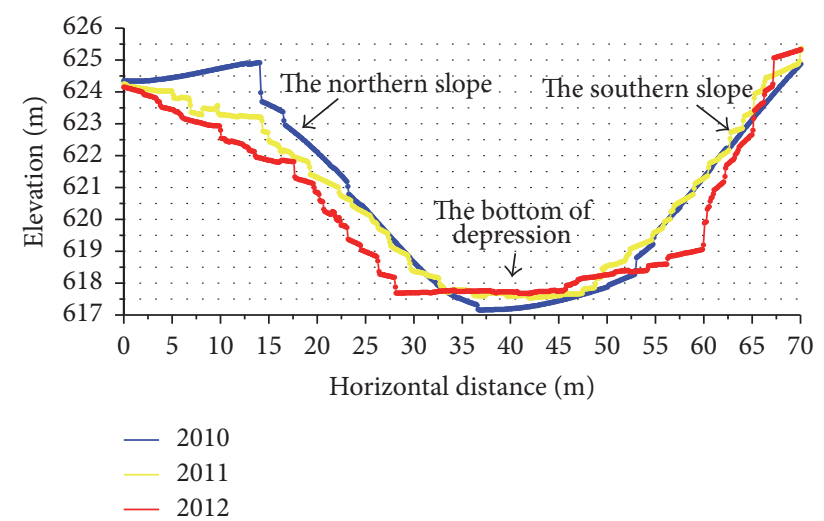

FIGURE 15: Transverse profile variations for compound blowout erosion depression zone from 2010 to 2012.

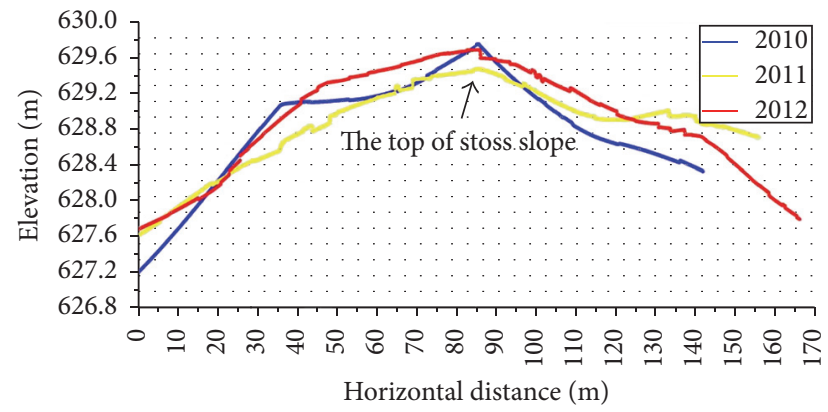

FIgURE 16: Transverse profile variations for sand deposition zone of compound blowout from 2010 to 2012.

$29.6 \mathrm{~m}$ at a speed of $14.8 \mathrm{~m} \cdot \mathrm{a}^{-1}$. The change was sizable from 2010 to 2011 at a movement of $29.5 \mathrm{~m}$ but minimal from 2011 to 2012 with a movement of only $0.1 \mathrm{~m}$. The boundary of sand deposition zone also moved southward by $24.1 \mathrm{~m}$ from 2010 to 2012 at a speed of $12.1 \mathrm{~m} \cdot \mathrm{a}^{-1}$.

\section{Discussion}

The shape and variation trends in the trough blowout were dependent mainly on wind entering the blowouts and accelerating continuously in the depressions due to funneling effect. There was no large-scale shrub coverage at the depression bottom, so the wind-drift sands were not effectively intercepted and thus caused severe erosion of the southern slopes, northern slopes, and depression bottom [14, 15]. Shallow depressions and gentle slopes at the southern and northern edges also allowed airflow to form a vortex which blew out from the relatively gentle northern edge to form a new air outlet, thereby leading to the appearance of a small fanshaped sand deposition zone at the northern part of the depression. Airflow compressed from the stoss slope toe due to the effect of topographic uplift. Wind speed continued to increase and caused severe erosion of the rear depression edge and soil layer, causing the soil layer to gradually disappear along the prevailing wind direction. In the lee slope, the airflow dispersed and wind gradually decelerated to weaken the transportation of sand materials, thereby resulting in gradual deposition of sands in the sand deposition zone. The zone was also found to be controlled primarily by northwest winds. After the sands were transported to the sand deposition zone, they moved southwestward along the prevailing wind direction; thus, slope crest of the zone moved southward and the zone boundary expanded to the south.

The erosion depression zone of the trough blowout first increased then decreased, likely due to weakened wind intensity from 2010 to 2011 having transported less sand material into the blowout. The wind's sand transporting ability weakened due to abatement. The lack of sand source caused the original sand deposition zone to decrease in elevation. From 2011 to 2012, large amounts of sand materials were transported to the sand deposition zone as the depressions were severely eroded by wind, thereby resulting in increased elevation of the zone's slope crest. The soil layer exposed at the rear depression edge moved forward along the long axis of the erosion depression as a result of continuous erosion attributed to elevated terrain, compressed airflow, and strengthened wind at the site.

The formation of the compound blowout can be attributed to the westerly and northwesterly prevailing wind directions in the area. When the wind entered the blowouts, the Salix psammophila shrubs grown at the depression bottom intercepted the wind-drifted sand materials causing them to accumulate continuously and result in ever shallower depth of depression. The shrubs also played a role in shunting wind-drift sands $[16,17]$ so that the airflow moved forward towards the rear depression edge along the northern and southern slopes to undercut them, thereby continuously increasing the depression width (Figure 17(a)) [18]. The sand materials severely eroded the soil layer at the rear depression edge beginning at the stoss slope toe due to the effects of terrain uplift, compressed airflow, and continuously accelerating wind after drifting, causing the soil layer to move along the long axis of blowout $[19,20]$. The wind decelerated after reaching the stoss slope crest where sand materials were deposited.

At the lee slope, airflow gradually dispersed, wind decelerated, and large amounts of sands accumulated in the sand deposition zone. Secondary blowouts appeared at the southern part of the lee slope due to wind erosion per the large coverage area of the compound blowout's sand deposition zone (Figure 17(b)). Parabolic dunes developed behind it [21]. Wind speed increased due to funneling in the recessed areas, where erosion was severe. Wind continued to accelerate at the stoss slope of the dunes and picked up large amounts of sand materials. On the lee slope of the dunes, sand materials deposited to continuously increase the elevation of the sand deposition zone. To this effect, the emergence of parabolic dunes led the depositional trend at the compound blowout's sand deposition zone and increased the elevation of the dune-side lee slope rather than gradually reducing the sand materials along the long axis. This is the primary difference between this zone and other simple blowout sand deposition zones.

It can be seen from the analysis of repeatedly measured ground high-precision GPS data that the trends of dynamic 


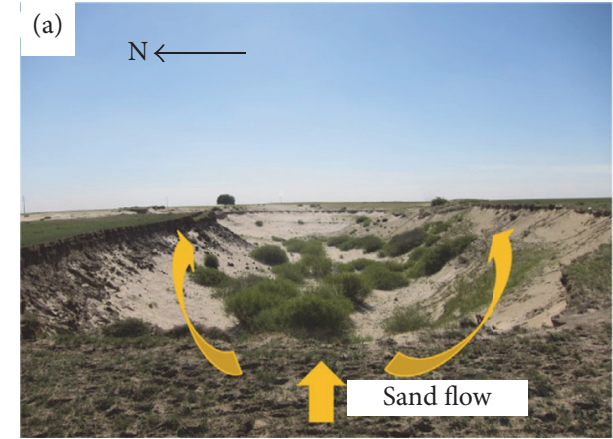

(a)

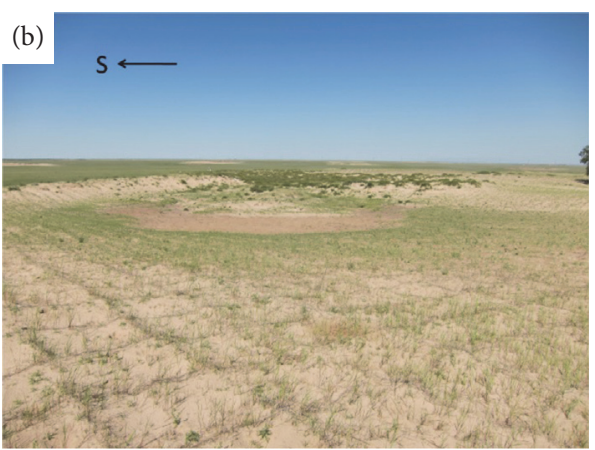

(b)

FigURE 17: Field photographs of compound blowout ((a) vegetation and airflow at the erosion depression, 2012; (b) secondary blowouts in the sand deposition zone, 2012).

changes varied for different types and sizes of blowouts from 2010 to 2012. As the smallest blowout selected, the length, width, and depth of the saucer blowout's erosion depression zone all experienced continuous increase, which appeared as a changing process of continuous erosion. The sand deposition zone, on the other hand, experienced a process of continuous deposition, thereby resulting in persistent increase in the elevation of its stoss slope crest. This was mainly because the saucer blowout had small form and shallow depression depth, so that the base level of erosion failed to reach the groundwater level. Therefore, the erosion depression zone presented a continuous erosion pattern, while the sand deposition zone was in a continuous deposition process. Compared to the saucer blowout, trough blowout had larger size and more complicated variation. Its erosion depression zone exhibited a first deposition then erosion process. This was probably due to the sidewall collapse between 2010 and 2011, which led to deposition of some sand materials at the bottom of depression. Moreover, wind's energy to transport sand materials in the erosion depression weakened, thereby causing increased depth of the depression during this stage. Because there was no sand source, and the sands in the original sand deposition zone was affected by wind erosion, the elevation decreased. Between 2011 and 2012, the depression was subject to strong wind erosion, so that substantial sand materials were transported into the sand deposition zone, thereby causing increased elevation of slope crest for the zone. Compound blowout had the largest and deepest sand depression zone. The length and width of the zone continued to increase, but the depression depth decreased gradually. This was mainly because the erosion depression zone was eroded to the groundwater level, so that the soil moisture content was high enough to develop largescale Salix psammophila shrubs. Besides, vegetation itself had a role in intercepting and shunting wind-drift sands, which allowed continuous deposition of sand materials to result in the shallower depth of depression. Moreover, its shunting effect led the airflow to advance towards the rear edge of the depression along the northern and southern slopes to undercut these slopes, thereby continuously increasing the depression width. In addition, the sand deposition zone of the compound blowout was once again subject to wind erosion due to its large size to develop secondary blowouts.

Within the study area, road was one of the main factors inducing the development of blowouts. Due to the automobile roller compaction, the surface vegetation of sandy grasslands was damaged, and the soil layer was exposed. By the undercutting effect of strong wind, the loose soil layer on the road was subject to strong wind erosion to develop into blowouts. Extensive beaded blowouts were developed within the study area, which belonged to a type of road blowouts (Figure 4(a)). The authors statistically analyzed the road area (Table 14) in 1959, 2002, 2004, 2009, and 2012 to find that the area increased by $488,581 \mathrm{~m}^{2}$ in total, which was an increase of $23.5 \%$. Meanwhile, with the development of animal husbandry, the pressure of grassland habitat in the study area has been exacerbating. Overgrazing resulted in degradation of grasslands and exposure of surface soil layer, which easily facilitated the formation of bare areas under wind erosion. From a cause analysis perspective, the desertification of Hulunbuir grassland was the result of the combined action of natural and human factors. The arid or semiarid climatic environment is the prerequisite for desertification, whereas the human destruction of grassland vegetation and surface soil layer is the direct cause of desertification. Therefore, engineering desertification control measures such as straw checkerboard barriers and vegetation planting, as well as policies such as rational development of grassland resources and rational road construction are the primary means of controlling the blowout expansion.

\section{Conclusion}

From 2002 to 2012, the erosion depressions of saucer, trough, and compound blowouts in the study area extended along the downwind direction, while expanding laterally and continually increasing in size. The saucer blowout area increased in the sand deposition zone, while areas of trough and compound blowouts first increased, then decreased, and then increased again over the study period: their area markedly increased from 2002 to 2004 , decreased to the minimum from 2004 to 2009, and then increased again from 2009 to 
TABLE 14: Variations in area of roads (unit: $\mathrm{m}^{2}$ ).

\begin{tabular}{lccccc}
\hline Year & 1959 & 2002 & 2004 & 2009 & 2012 \\
\hline The area of roads & $2,080,425$ & $2,282,358$ & $2,312,852$ & $2,505,163$ & $2,569,006$ \\
\hline
\end{tabular}

2012. Changes in the sand drift zone were rather complex. The trough blowout continued to decrease until reaching the minimum in 2012. Compound and saucer blowouts continued to decrease from 2002 to 2009 , reached their respective minima in 2009, and then increased again from 2009 to 2012.

Our analysis of 3D data from repeated ground surveys indicates that the saucer blowout is the smallest in scale of all three blowout types, though it is in a period of active development. From 2010 to 2012, its erosion depression exhibited a downward erosion and horizontal expansion trend. Its sand deposition zone, conversely, presented an accumulation pattern. Its length decreased while its width and slope crest elevation increased. Sands deposited in the southeasterly direction due to the influence of resultant drift potential. The trough erosion depression increased in length and width and expanded horizontally, but its depth increased first and then decreased (i.e., first accumulated and then eroded). Its sand deposition zone exhibited the opposite pattern (first erosion and then accumulation). Its length decreased and its width increased, while its apex elevation first decreased and then increased. The erosion depression of the compound blowout expanded horizontally as-affected by northwestern and western winds; its area, length, and width continually increased over the study period. As Salix psammophila shrubs at the bottom of the depression intercepted the wind-drifted sand materials, they continued to accumulate at the depression bottom resulting in ever shallower depression depth. In the sand deposition zone, sand materials continued to accumulate, thereby resulting in continuous elevation of the slope crest. We also observed the development of secondary blowouts and parabolic dunes.

\section{Conflicts of Interest}

The authors declare that they have no conflicts of interest.

\section{Acknowledgments}

This research was supported by "the National High Technology Research and Development Program of China (Grant no. 2016YFC0500805)" and the National Natural Science Foundation of China Project "Formation and Deformation of Reticulate Dune Patterns in Hobq Desert (Grant no. 41671002)." The authors are grateful to Liu Dan and Zhou Yanguang for their assistance in the field.

\section{References}

[1] D. P. Zhang, X. K. Wang, E. D. Hasi et al., "HulunBuir sandy grassland blowouts I geomorphology, classification, and significances," Journal of Desert Research, vol. 26, no. 6, pp. 894-902, 2007.
[2] D. P. Zhang, H. W. Sun, X. K. Wang et al., "HulunBuir sandy grassland blowouts II: process of development and landscape evolution," Journal of Desert Research, vol. 27, no. 1, pp. 20-24, 2007.

[3] D. P. Zhang, X. K. Wang, R. L. Hu et al., "HulunBuir Sandy grassland blowouts III influence of soil layer and micro-relief," Journal of Desert Research, vol. 27, no. 1, pp. 25-31, 2007.

[4] D. P. Zhang, X. K. Wang, H. W. Sun et al., "HulunBuir Sandy grassland blowouts IV influence of human activities," Journal of Desert Research, vol. 27, no. 2, pp. 214-220, 2007.

[5] J. L. Dong and J. Ya, "Analysis on the changes of land desertification in hulunbeier sandy land area over the last 10 years," in Forest Resources Management, pp. 39-43, 2002.

[6] J. M. Feng and T. Wang, "Study on the actualty and historical evolution of desertification in the HulunBuir grasslands," Arid Land Geography, pp. 356-360, 2004.

[7] H. G. Nie, L. P. Yue, W. Yang et al., "Present situation, evolution trend and causes of Sandy desertification in Hulunbuir steppe," Journal of Desert Research, vol. 25, no. 5, pp. 635-639, 2005.

[8] G. S. Zan and T. Sun, "Vegetation cover change on Hulun Buir grassland," Forest Resources Management, no. 1, pp. 44-48, 2011.

[9] P. Zhang, E. D. Hasi, S. Wang, and S. Zhang, "Zonation of vegetation on depositional area of blowout in Hulun Buir grassland," Journal of Natural Resources, vol. 23, no. 2, pp. 237-244, 2008.

[10] L. Man, E. D. Hasi, P. Zhang et al., "Micro-community characteristics of vegetations on blowouts and depositional areas of HulunBuir Grassland, Inner Mongolia," Chinese Journal of Applied Ecology, vol. 19, no. 10, pp. 2177-2181, 2008.

[11] H. S. Du, E. D. Hasi, Y. Yang et al., "Land-cover landscape changes of blowouts distribution in the HulunBuir Grassland," Journal of Arid Land Resources and Environment, pp. 129-134, 2013.

[12] S. G. Fryberger and G. Dean, "Dune forms and wind regime," in A Study of Global Sand Seas, E. D. McKee, Ed., pp. 137-169, U.S. Geological Survey Publications Warehouse, 1979.

[13] Y. J. Fang, J. F. Zhao, Y. P. Guo et al., "Magnitude deviations of sand drift potential calculation in the 'FRYBERGER' model: a case of the Taklimakan Desert," Arid Land Geography, no. 1, pp. 95-112, 2015.

[14] P. D. Jungerius, J. V. Witter, and J. H. van Boxel, "The effects of changing wind regimes on the development of blowouts in the coastal dunes of The Netherlands," Landscape Ecology, vol. 6, no. 1-2, pp. 41-48, 1991.

[15] P. A. Gares and K. F. Nordstrom, "A cyclic model of foredune blowout evolution for a leeward coast: Island Beach, New Jersey," Annals of the Association of American Geographers, vol. 85, no. 1, pp. 1-20, 1995.

[16] J. S. Olson, "Lake michigan dune development 2. Plants as agents and tools in geomorphology," The Journal of Geology, vol. 66, no. 4, pp. 345-351, 1958.

[17] E. C. Hu, X. J. Wang, and W. J. Zhang, "Analysis on spatial pattern of blowouts in otindag sandy grassland based on ALOS data," Desert and Desertification, vol. 33, no. 3, pp. 662-667, 2013.

[18] C. H. Hugenholtz and S. A. Wolfe, "Morphodynamics and climate controls of two aeolian blowouts on the northern Great 
Plains, Canada," Earth Surface Processes and Landforms, vol. 31, no. 12, pp. 1540-1557, 2006.

[19] G. S. Fraser, S. W. Bennett, G. A. Olyphant et al., "Windflow circulation patterns in a coastal dune blowout, south coast of Lake Michigan," Journal of Coastal Research, vol. 14, no. 2, pp. 451460, 1998.

[20] M.-L. Byrne, "Seasonal sand transport through a trough blowout at Pinery Provincial Park, Ontario," Canadian Journal of Earth Sciences, vol. 34, no. 11, pp. 1460-1466, 1997.

[21] P. A. Hesp and R. Hyde, "Flow dynamics and geomorphology of a trough blowout," Sedimentology, vol. 43, no. 3, pp. 505-525, 1996. 


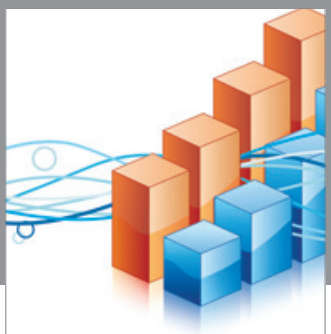

Advances in

Operations Research

vatem alat4

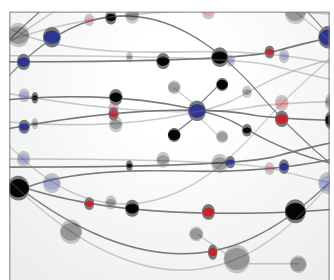

\section{The Scientific} World Journal
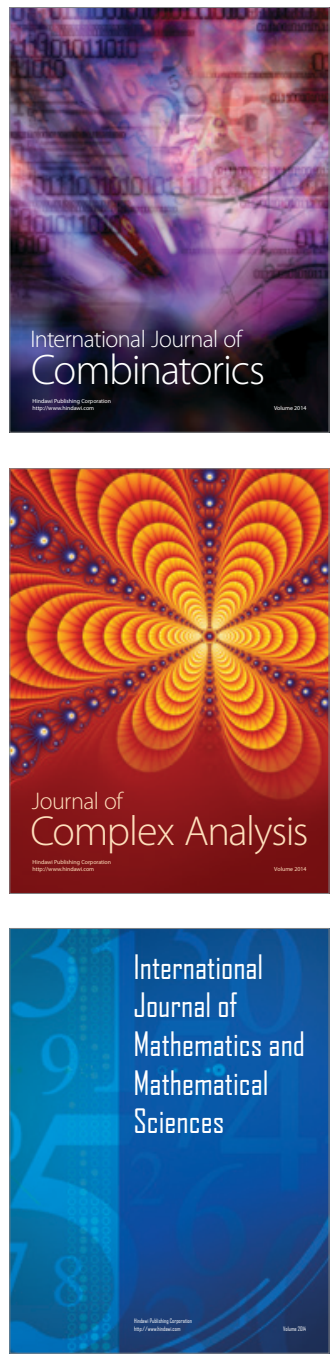
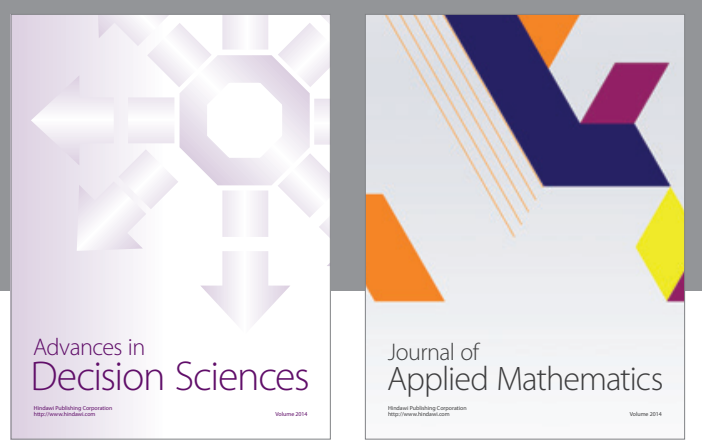

Algebra

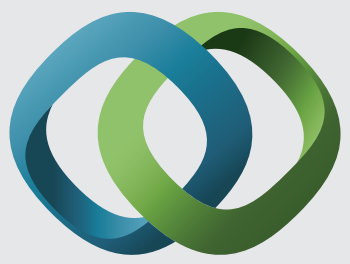

\section{Hindawi}

Submit your manuscripts at

https://www.hindawi.com
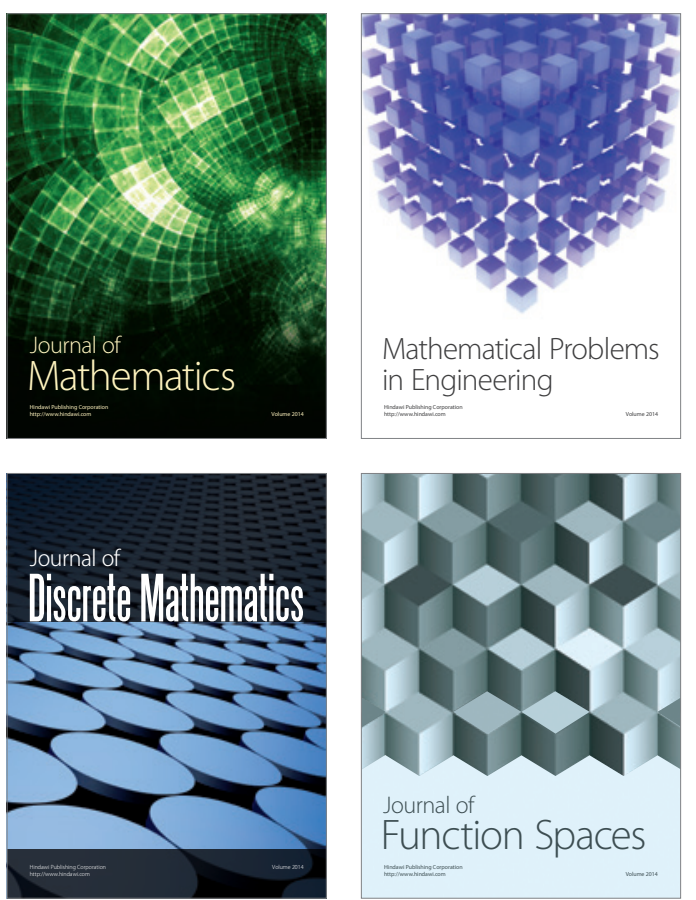

Mathematical Problems in Engineering
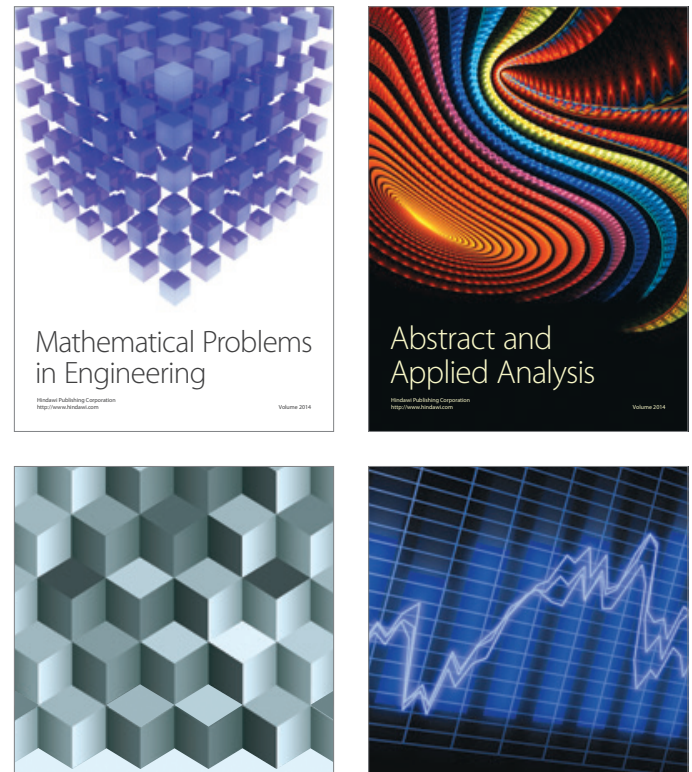

Journal of

Function Spaces

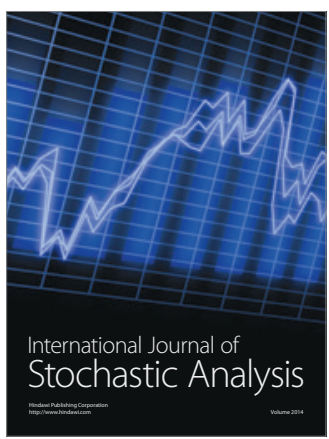

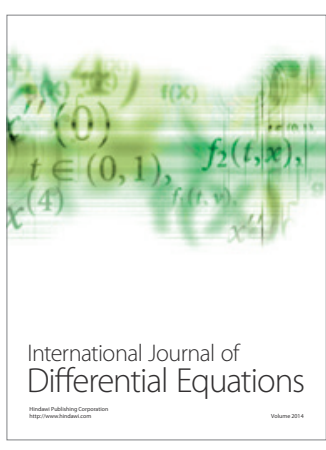
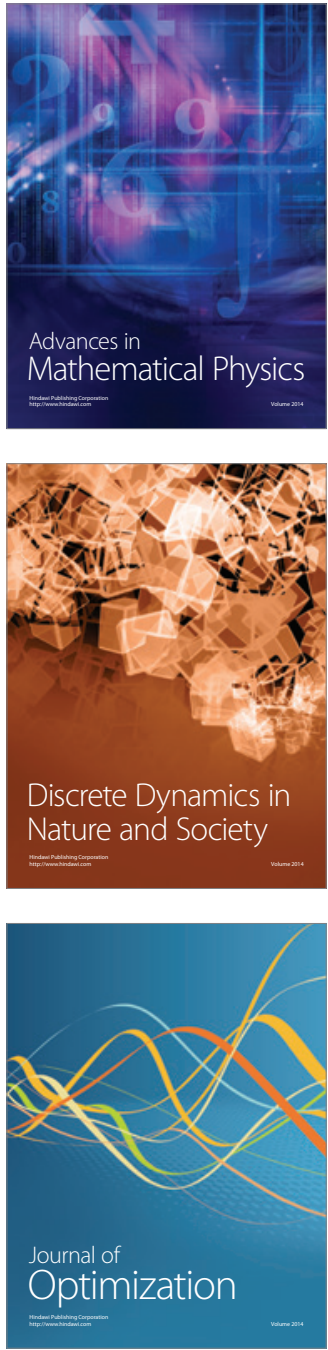